\title{
Innovative approach for geospatial drought severity classification: a case study of Paraíba state, Brazil
}

\author{
Celso Augusto Guimarães Santos ${ }^{1}$ (D) $\cdot$ Reginaldo Moura Brasil Neto $^{1}$ (D) $\cdot$ Richarde Marques da Silva $^{2}$ (1) \\ Daris Correia dos Santos ${ }^{1}$
}

Published online: 17 October 2018

(C) The Author(s) 2018

\begin{abstract}
Trend analysis of droughts and their geospatial and temporal variability assists decision-making about water resources management around the world and decreases the harmful effects of drought that affect the entire population. This work aimed to analyze short-, medium- and long-term droughts and their trends in the Brazilian state of Paraíba from 1998 to 2015 using Tropical Rainfall Measuring Mission (TRMM) data and applying the Mann-Kendall test and Sen's slope estimator method, based on the standardized precipitation index (SPI). TRMM data were validated by comparison with data from 267 rain gauges in the region, which showed the consistency of the satellite data. Therefore, 187 monthly TRMM rainfall time series were used, each with 216 months. The series were equally distributed over the entire study area. At the significance level of 0.01 , a new geospatial classification of drought severity is proposed, through which it is possible to determine exactly which types of drought events affected or did not affect a given region based on the SPI and the trend of the analyzed SPI time series, which shows the situation of drought risk analysis. The results of the comparison between long- and short-term droughts indicate that the wettest regions of the state of Paraíba are strongly affected by extreme drought events and show trends with increasingly negative slopes. In this way, the proposed geospatial classification is proved to be a useful tool because it provides information about the current drought situation of a given region, simultaneously showing the trend slope with respect to short-, medium- and long-term droughts.
\end{abstract}

Keywords Brazil $\cdot$ Drought $\cdot$ Semi-arid region $\cdot$ SPI $\cdot$ Trend $\cdot$ TRMM

\section{Introduction}

Drought is one of the most complex, important and recurring phenomena on the Earth, which affects agriculture in various territories and especially in arid and semiarid regions (Mansouri Daneshvar et al. 2013; Mathbout et al. 2018). This phenomenon has impacts on different aspects of society, such as socioeconomic, biological, social, agricultural and political. Furthermore, drought is one of the most poorly understood natural phenomena and is perceived as one of the most expensive (Wang et al.

Celso Augusto Guimarães Santos celso@ct.ufpb.br

1 Department of Civil and Environmental Engineering, Federal University of Paraíba, João Pessoa, PB 58051-900, Brazil

2 Department of Geosciences, Federal University of Paraíba, João Pessoa, PB 58051-900, Brazil
2014). Therefore, analysis of drought and its severity for a river basin that supports agriculture and other human needs is necessary for better planning and management of its water resources (Thomas et al. 2015).

The monitoring of different types of drought is based on indices that standardize on temporal and regional scales, such as: (a) the Palmer Drought Severity Index-PDSI (Palmer 1965), (b) the Standardized Precipitation IndexSPI (McKee et al. 1993; Wilhite et al. 2000) and (c) the Standardized Precipitation Evapotranspiration IndexSPEI (Vicente-Serrano et al. 2010), which allow comparisons of water conditions in different areas. Such indices have been used in state and federal policies as parameters to assist decision-making regarding the adoption of plans to combat the implications of drought in various sectors of society (Rossato et al. 2017). Nevertheless, it has been difficult to establish one universal index to monitor drought (Heim 2002), but among the existing indices, the SPI has 
the advantage of requiring only rainfall data for computations and can be compared across regions with different climatic zones (WMO 2012; Zhang et al. 2017; Faiz et al. 2018; Park et al. 2018; Santos et al. 2017). The SPI has other advantages of statistical consistency and the ability to describe both short- and long-term drought impacts through the different time scales of precipitation anomalies (Cancelliere et al. 2007). The SPI is fitted to a gamma probability distribution, which is then transformed into a normal distribution so that the mean value of the index for the location and desired period is zero (Mansouri Daneshvar et al. 2013). On the other hand, one of the most commonly used techniques to study the impact and spatiotemporal variations of rainfall is the analysis of trends in SPI (e.g., Wang et al. 2014; Achugbu and Anugwo 2016).

Tests for the detection of significant trends in hydroclimatologic time series can be classified as parametric and non-parametric methods (e.g., Tabari et al. 2011; Silva et al. 2015; de Brito Neto et al. 2016). In many studies, the non-parametric Mann-Kendall trend test and Sen's slope estimator method are applied to identify trends and determine their magnitudes in time series (e.g., Partal and Kahya 2006; Wang et al. 2014; Achugbu and Anugwo 2016). Previous climate research in Paraíba state, however, has seldom applied the SPI to identify drought severity (Macedo et al. 2010; Farias et al. 2014) nor identified any trends. In addition, while these previous studies in the region used a data network poorly distributed across the state, the present study uses 187 continuous daily rainfall time series over 18 years, and with these data, eight different SPIs and their respective trends are calculated through a joint application of Mann-Kendall and Sen tests. For this reason, in this study, the SPI is used to detect and characterize the temporal variability of drought in Paraíba state over the period 1998-2015 using Tropical Rainfall Measuring Mission (TRMM) data.

To analyze rainfall, rain gauges are the main measuring method, but in some countries such as Brazil, the network of these gauges is not regular enough, and in some regions, the gauges are either scarce or concentrated. In this sense, radar data using space-borne sensors provide an excellent complement to monitoring continuous rainfall events at the spatial and temporal scales (Zeng et al. 2012). Thus, the TRMM (Kummerow et al. 1998; Park et al. 2018; Santos et al. 2018) has been an accurate alternative source of rainfall data, which provides the opportunity for fine spatial-temporal rainfall products. The accuracy of the TRMM data has already been tested in several studies around the world, and Pereira et al. (2013) and Soares et al. (2016) have already proven that precipitation estimates using TRMM satellites reproduce the spatial-temporal pattern of the rainfall regime both in terms of seasonality and spatial distribution in Brazil and Paraíba state, respectively. In addition, the agreement between the TRMM and the rain gauge data increases for larger time accumulation scales; thus, on a monthly scale, the correlation values found are significant. However, a small number of studies have been done using TRMM rainfall data for drought monitoring in northeastern Brazil.

Nevertheless, to characterize the drought behavior, a dense and continuous data network is necessary to guarantee homogeneity and robustness of the results. Therefore, the TRMM rainfall database is suitable for the present study because it provides a continuous and well-distributed rainfall database over the region to be analyzed. The rain gauge network in the state of Paraíba, as in several other Brazilian states, presents a poor spatial distribution and has many flaws in its historical series. Paraíba has been one of the Brazilian states most affected by droughts in the last decades (Marengo et al. 2017). Drought hazards occur frequently in this region and have caused huge agricultural and socioeconomic losses. Severe water scarcity is the key problem for the development of the region, and the unevenly distributed rainfall over the year causes Paraíba to suffer from the most severe soil erosion (Xavier et al. 2016; Silva et al. 2018) and erosivity (Silva et al. 2013) in the world, beyond the picture of aggravated water scarcity in recent years. However, few studies have analyzed the severity of historical droughts in the region.

Thus, the present study provides a novel geospatial drought severity classification method to simultaneously identify short-, medium- and long-term droughts and their trends over any area of interest, and the Paraíba state is used as a case study for the application of such an innovative approach. The next sections briefly describe the study area, data, methodology and obtained conclusions.

\section{Study area and data description}

\subsection{Study area}

The state of Paraíba has a total area of $56,469.78 \mathrm{~km}^{2}$, and it is divided into four mesoregions: Agreste, Borborema, Mata and Sertão (Fig. 1a). The relief of the state varies from lowlands at the coast to depressions in the Sertão of Paraíba state. In the coastal area (Mata mesoregion), the climate is classified as a humid tropical climate with mean temperatures of approximately $24{ }^{\circ} \mathrm{C}$. The annual mean rainfall is $1400 \mathrm{~mm}$. There are two seasons in Paraíba state, a drought season in the summer and a rainy one in the autumn and winter. The predominant climate in the state's interior, beyond the Borborema mountain range, is semiarid, characterized by scarce and irregular rain and low rainfall, which is sometimes less than $500 \mathrm{~mm}$ per year. Cabaceiras county, in the mesoregion of Borborema, holds 
(a)

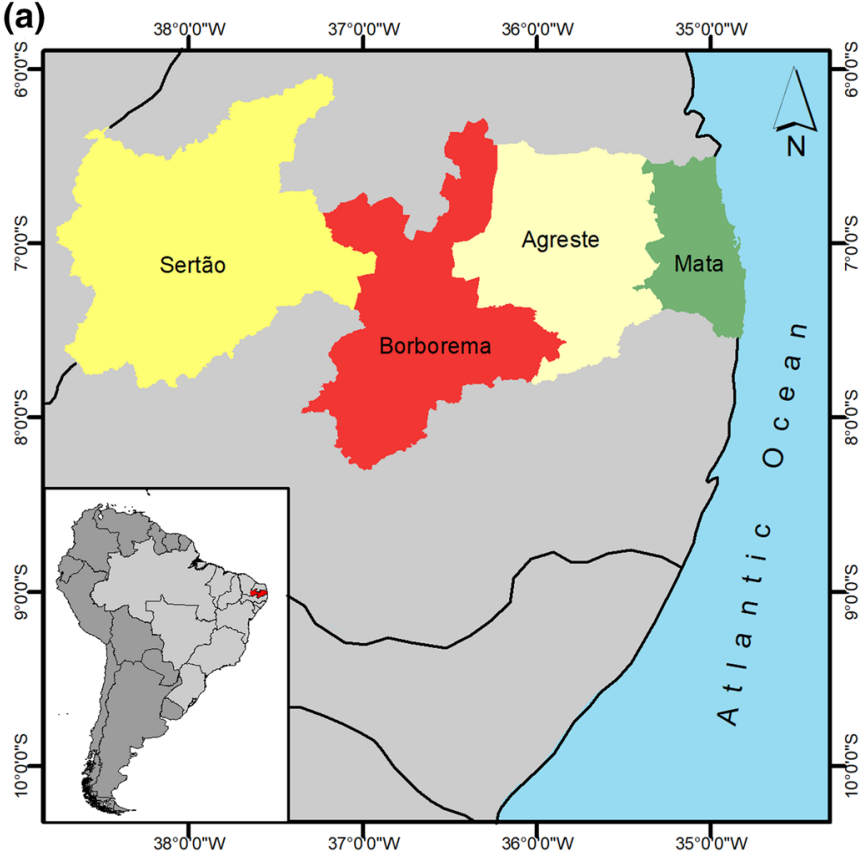

(b)

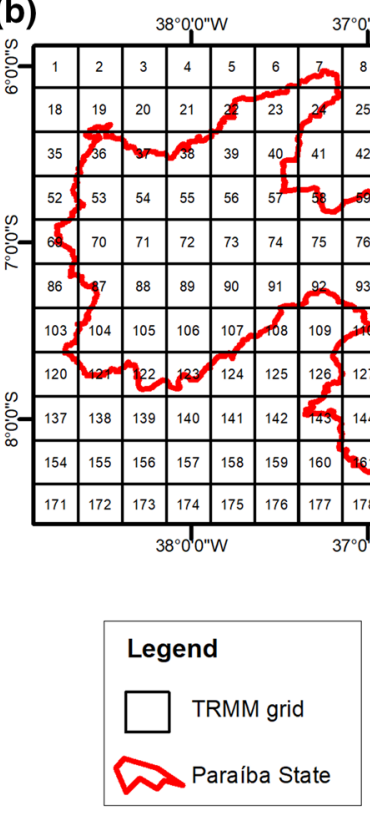

Fig. 1 a The state of Paraíba with its mesoregions and $\mathbf{b}$ the study area with the distribution of 187 grid points for the time series of the TRMM data

the title of the driest municipality in Brazil, with rainfall below $300 \mathrm{~mm}$ per year. Along with climate, vegetation varies according to the relief. On the coastline, the vegetation cover consists of coastal plateaus with abundant bushes and grasses. In the Sertão mesoregion, especially beyond the formation of the Borborema Plateau, the most abundant vegetation is caatinga, composed of tree species such as baraúna and bushes. Thus, the study area is the rectangle that surrounds the state of Paraíba, defined by the coordinates $38.875^{\circ} \mathrm{W}$ to $34.625^{\circ} \mathrm{W}$ and $5.875^{\circ} \mathrm{S}$ to $8.625^{\circ} \mathrm{S}$ (Fig. 1b).

\subsection{Precipitation data}

The main purpose of this study is to spatially classify drought severity based on the rainfall data of approximately the last two decades. To use complete time series equally distributed across the entire study area, daily precipitation data of the TRMM satellite (3B42 product, version 7) are used. The TRMM is a joint NASA-JAXA satellite mission that was launched near the end of 1997 (Huffman et al., 2007; Nóbrega et al. 2008; Santos et al. 2017). The study area is divided into 187 grid cells $(11 \times 17)$, whose centroids (grid points) are equally spaced every $0.25^{\circ}$ from $38.75^{\circ} \mathrm{W}$ to $34.75^{\circ} \mathrm{W}$ and from $6.00^{\circ} \mathrm{S}$ to $8.50^{\circ} \mathrm{S}$, as shown in Fig. $1 \mathrm{~b}$. The series of the total daily rainfall for each cell $\left(0.25^{\circ} \times 0.25^{\circ}\right)$ was obtained for the period between January 1st, 1998, and December 31st, 2015.
Figure 2 shows the interpolation of the total precipitation at each grid point by using the spline method for each year, based on the TRMM, while Fig. 3 shows the distribution of the annual mean rainfall across the study area. Figure 2 reveals that the last 4 years have witnessed the lowest rainfall levels; the year 2012, the driest year, stands out with an average value of approximately $400 \mathrm{~mm}$ across the study area. On the other hand, the years 2000, 2004, 2008 and 2009 were the wettest years of the study time series, with annual mean precipitation levels greater than $1100 \mathrm{~mm}$. In general, the coastal region (Mata region) has the highest rainfall levels, inland Paraíba (the Sertão region) has intermediate rainfall levels, and the central region of Paraíba (Borborema region) has the lowest rainfall levels, as summarized in Fig. 3.

\subsection{Validation of the TRMM data}

As the rain gauge network in the state of Paraíba, and several other states, has a poor spatial distribution and many missing data in its historical series, TRMM data were used. However, to validate the TRMM data and the rain gauge network data, an analysis of the spatial distribution of the rain gauge stations and of the correlation between monthly TRMM data and rain gauges was performed, as the monthly total precipitation levels are used to calculate the SPI. Based on the geographic coordinates and on the historical series of the 267 rain gauge stations in the state of Paraíba between 1998 and 2015, the monthly precipitation 
(a) 1998

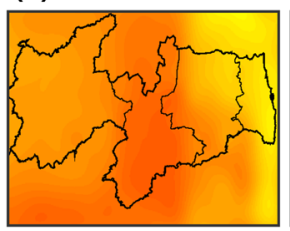

(b) 1999

(c) 2000
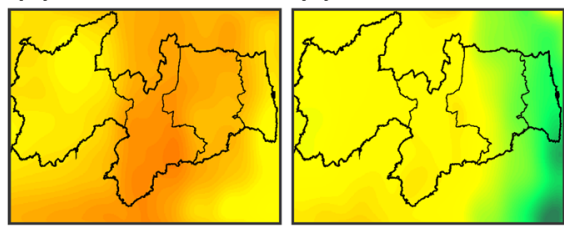

(d) 2001

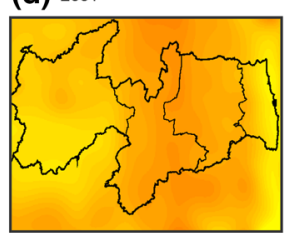

(e) 2002
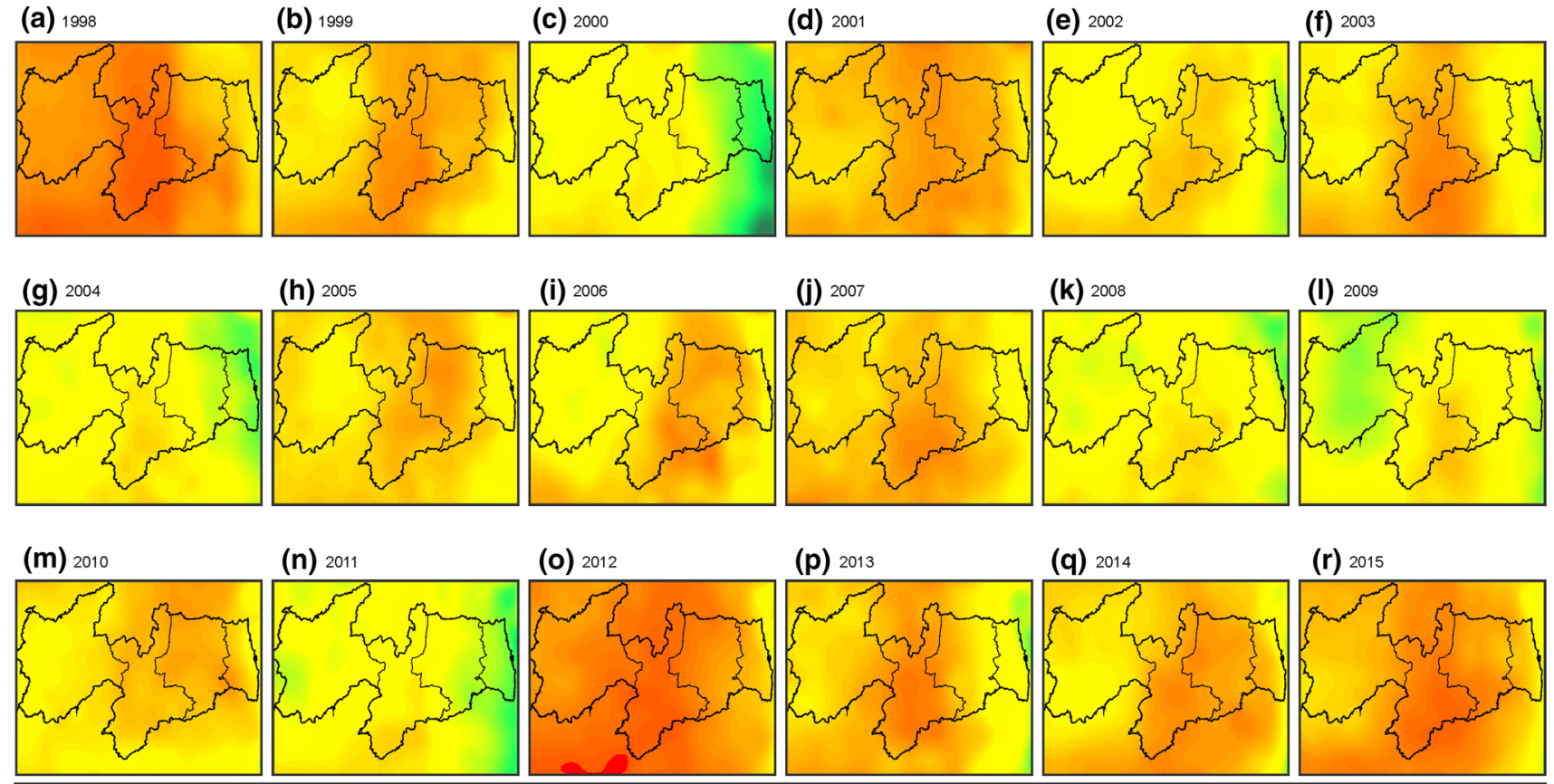

(o) 2012

(p) 2013

(q) 2014

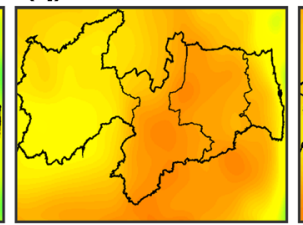

(r) 2015
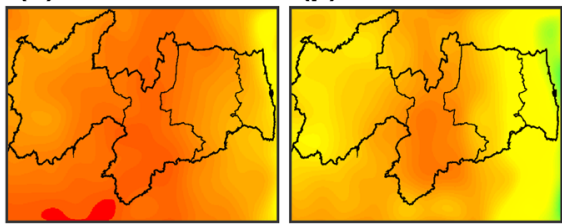

2000

Precipitation (mm)

Fig. 2 Spatial distribution of the annual precipitation in the state of Paraíba (1998-2015)

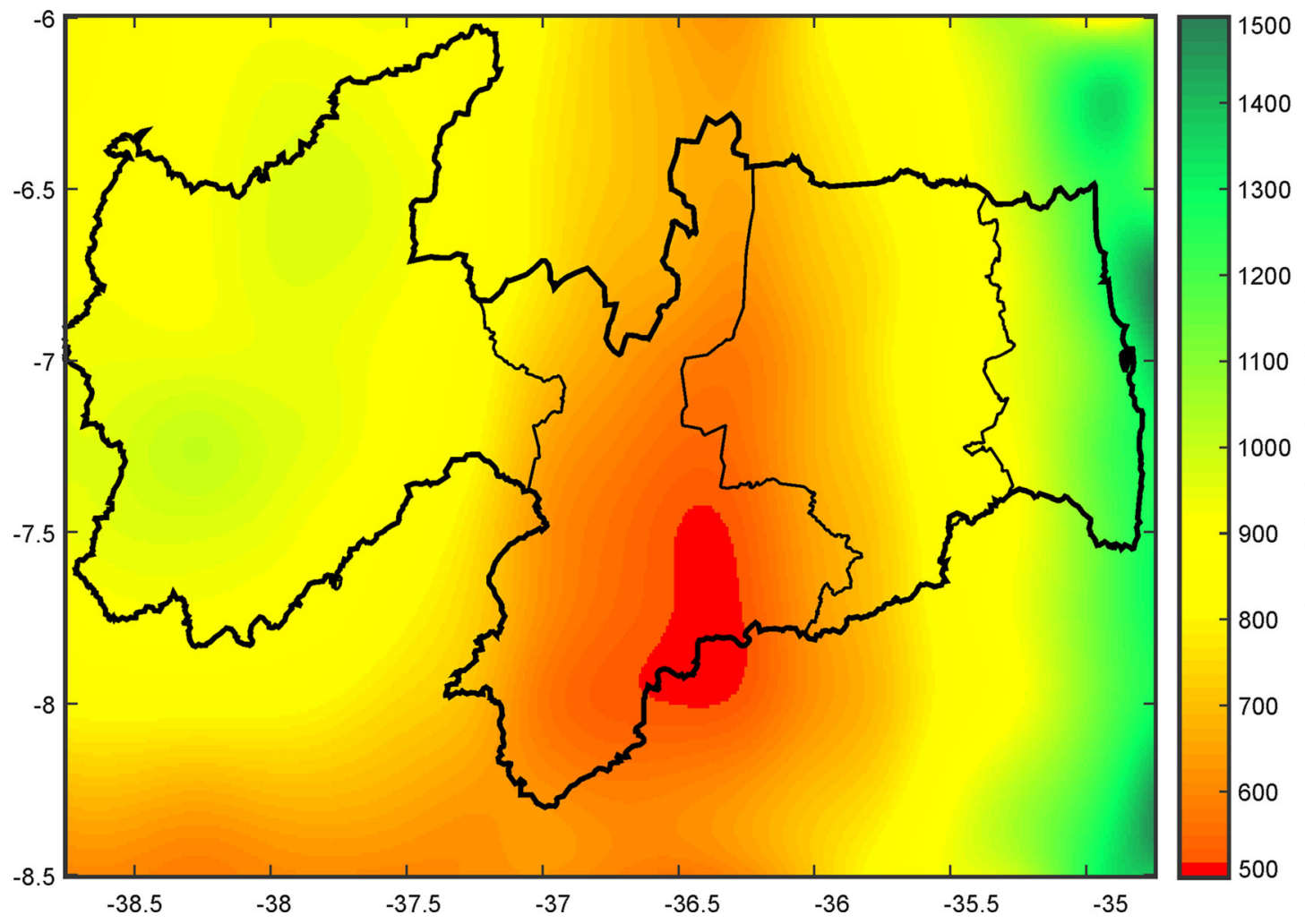

Fig. 3 Spatial distribution of the annual mean precipitation in the state of Paraíba (1998-2015) 


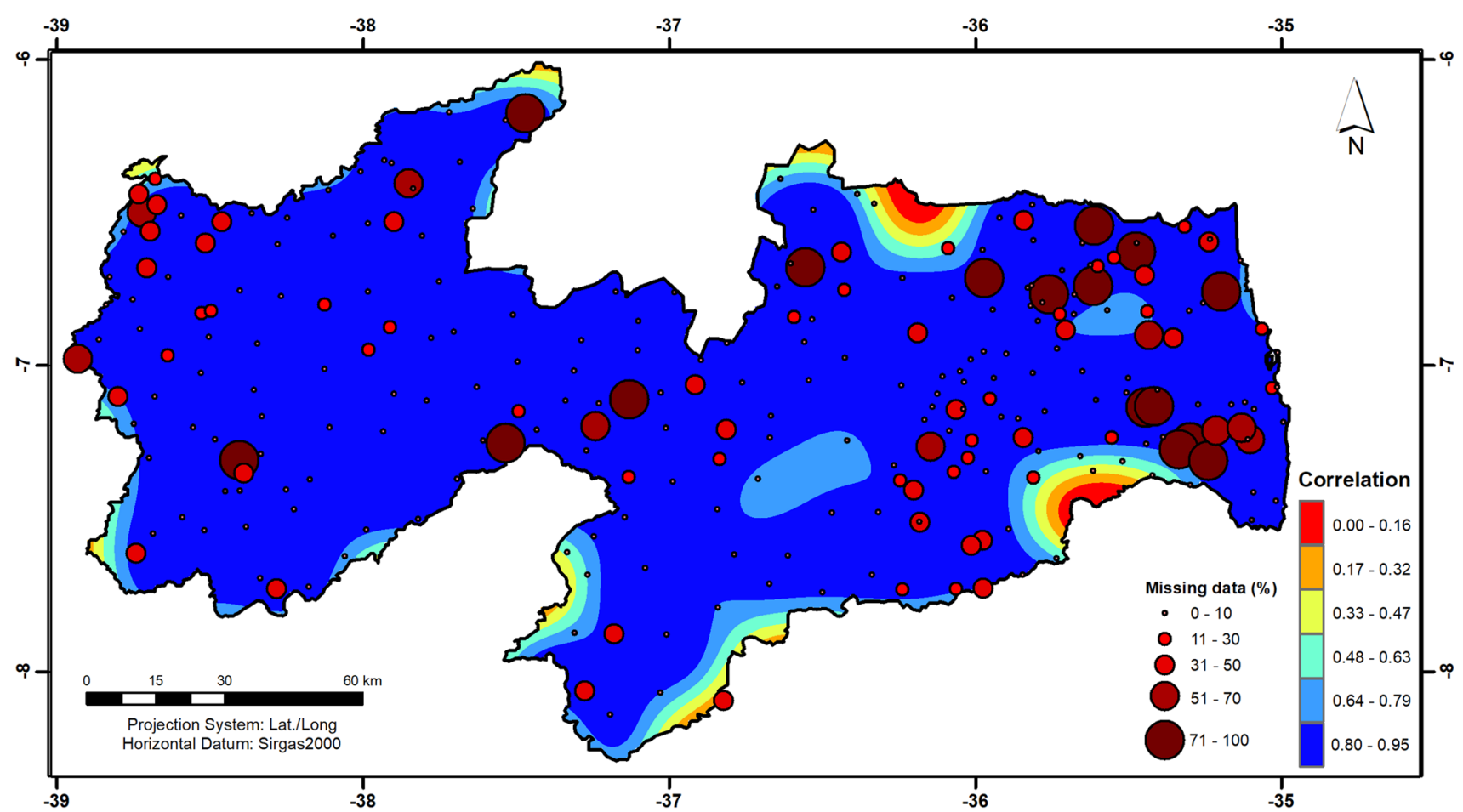

Fig. 4 Locations of the rain gauge stations with the percentage of missing data and spatial distribution of the correlation coefficient between monthly TRMM precipitation data and the average of the

monthly total data of the rain gauge stations in the grid in the state of Paraíba (1998-2015)

values of each grid point of the TRMM were compared with the mean values of the data observed in the rain gauges located at each grid, as in Nicholson et al. (2003) for West Africa. Figure 4 shows the locations of the rain gauge stations in Paraíba, whose size/color respectively represents the percentage of missing data in the time series of that station and the correlation coefficient between the monthly TRMM precipitation data and the average of the monthly total data of the rain gauge stations located in the grid, disregarding errors, between 1998 and 2015.

Based on Fig. 4, the spatial distribution of the rain gauge stations in the state of Paraíba shows that some areas have more than eight rain gauge stations per grid, while other regions have only one rain gauge station per grid. The mesoregions of Mata and Agreste are the areas with the best rain gauge station density, while the Sertão and Borborema regions have fewer rain gauge stations. In addition, although Mata has one of the highest concentrations of rain gauge stations in the state, it also shows a greater percentage of missing data per month, approximately $30 \%$. The other mesoregions also show a significant number of errors, which demonstrates the uneven distribution of the rain gauge stations in the state of Paraíba and the presence of several series with errors during the period analyzed.

Figure 4 also shows the distribution of the correlations between the monthly data of the rain gauges and the TRMM data. The analysis of Fig. 4 reveals that almost all the state of Paraíba shows significant levels of correlation and that, in the coastal area of the state, the values of the correlation coefficient are slightly lower compared with the values found inland; however, the order of magnitude of the correlation values is basically higher than 0.80 across the entire state. Thus, as a final conclusion, the TRMM data for the study period were used to spatially classify drought severity because such data provide a good representation of precipitation behavior in the state of Paraíba.

\section{Methodology description}

\subsection{Standardized Precipitation Index-SPI}

The SPI is a measure of rainfall deficit that is uniquely related to probability and was introduced by McKee et al. (1993) to measure drought severity. In this study, the SPI was calculated using TRMM data for each grid (187 time series). These precipitation data were organized into a gamma distribution range and then transformed into a standard normal distribution, i.e., with a mean of 0 and a standard deviation of 1 (Fig. 5), in which negative SPI values indicate that the precipitation levels were lower than average and vice versa.

Figure 5 shows the relationship between the SPI classification and the normal curve. The class near the norm 


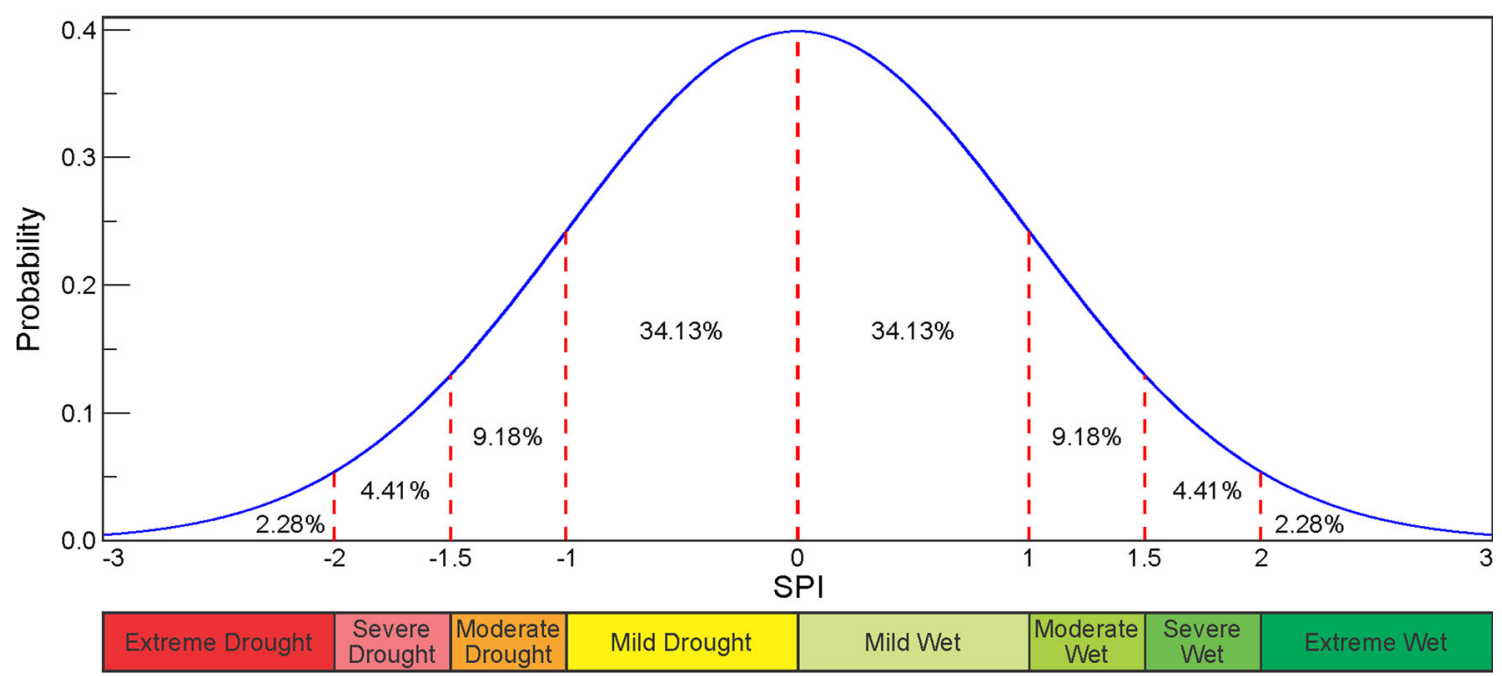

Fig. 5 Probability distribution of SPI and drought classification

would be the combination of two classes: $-1.0 \leq \mathrm{SPI}$ $\leq 0.0$ (mild drought) and $0.0<\mathrm{SPI} \leq 1.0$ (mild wet) (Ashraf and Routray 2015). The percentages in the regions bounded by the dashed and blue lines indicate the probability for SPI values to fall within that region; global cumulative probabilities correspond to the total area under the curve between two boundaries of interest. For example, SPI values of -1.0 or lower occur in only $15.87 \%$ (i.e., $2.28 \%+4.41 \%+9.18 \%$ ) of the cases.

The total rainfall for each grid of interest and the time scale are set into a gamma distribution. Then, the cumulative probability $H(x)$ is transformed into the standard normal variable $Z$ with a zero mean and a variance of one, which is the SPI value. More details may be found in Santos et al. (2017). Finally, according to the obtained $Z$ value, these total rainfall data can be classified as drought for values less than or equal to zero and wet for positive values, and as mild $(0.0<|\mathrm{SPI}| \leq 1.0)$, moderate $(1.0<|\mathrm{SPI}| \leq 1.5), \quad$ severe $\quad(1.5<\mathrm{ISPI} \mid \leq 2.0) \quad$ and extreme $(2.0<|\mathrm{SPI}| \leq 3.0)$.

\subsection{Mann-Kendall nonparametric trend test}

Two types of nonparametric statistical analyses were performed (the data need not conform to any particular distribution). First, the presence of a monotonic increasing or decreasing trend was tested with the Mann-Kendall test, and second, the slope of a linear trend was estimated with Sen's method, based on Salmi et al. (2002). These methods offer many advantages that have made them useful in analyzing rainfall data. Sen's method is not greatly affected by single data errors or outliers and uses a linear model to estimate the trend slope, but the variance of the residuals should be constant in time. The Mann-Kendall test is applicable in cases when the data values $x_{i}$ of a time series can be assumed to obey the model:

$x_{i}=f\left(t_{i}\right)+\varepsilon_{i}$

where $f(t)$ is a continuous monotonic increasing or decreasing function of time, and the residuals $\varepsilon_{i}$ can be assumed to be from the same distribution with zero mean; it is also assumed that the variance of the distribution is constant in time. The objective is to test the null hypothesis of no trend, $H_{0}$, against the alternative hypothesis, $H_{1}$, where there is an increasing or decreasing monotonic trend.

In the computation of this statistical test, both the socalled $S$ statistics given in Gilbert (1987) and the normal approximation ( $Z$ statistics) are exploited. For time series with fewer than 10 data points, the $S$ test is used, and for time series with 10 or more data points, as in the present case, the normal approximation is used.

The number of monthly values in the studied data series is denoted by $n$. As missing values are allowed, $n$ may be less than the total number of months. However, there are no missing values in the present study. The Mann-Kendall test statistic $S$ is calculated using the formula:

$\sum_{k=1}^{n-1} \sum_{j=k+1}^{n} \operatorname{sgn}\left(x_{j}-x_{k}\right)$

where $x_{j}$ and $x_{k}$ are the annual values in years $j$ and $k, j>k$, respectively, and

$\operatorname{sgn}\left(x_{j}-x_{k}\right)= \begin{cases}1 & \text { if } x_{j}-x_{k}>0 \\ 0 & \text { if } x_{j}-x_{k}=0 \\ -1 & \text { if } x_{j}-x_{k}<0\end{cases}$

The minimum values of $n$ depend on the set significance level. For example, for a significance level of 0.01 , the required minimum value of $n$ is 6 . The significance level 
0.01 means that there is a $1 \%$ probability of making a mistake when $H_{0}$ of no trend is rejected. Thus, the significance level 0.01 means that the existence of a monotonic trend is very probable.

For $n$ greater than or equal to 10 , the normal approximation test is used. However, if there are several equal values (i.e., tied values) in the time series, this situation should reduce the validity of the normal approximation when the number of data is close to 10 , but we are dealing with at least 169 values of SPI for each time series (grid). The variance of $S$ is computed by Eq. (2), taking into account that there may be ties:

$\operatorname{VAR}(S)=\frac{1}{18}\left[n(n-1)(2 n+5)-\sum_{p=1}^{q} t_{p}\left(t_{p}-1\right)\left(2 t_{p}+5\right)\right]$

in which $t_{p}$ is the number of data values in the $p$ th group, and $q$ is the number of tied groups. The test statistic $Z$, which has a normal distribution, is computed based on the values of $S$ and $\operatorname{VAR}(S)$ :

$Z= \begin{cases}\frac{S-1}{\sqrt{\operatorname{VAR}(S)}} & \text { if } S>0 \\ 0 & \text { if } S=0 \\ \frac{S+1}{\sqrt{\operatorname{VAR}(S)}} & \text { if } S<0\end{cases}$

Then, such a $Z$ value is used to evaluate whether there exists a statistically significant trend in the time series, in which a negative $Z$ value would indicate a downward trend, whereas a positive value would indicate an upward trend. To test for either a downward or upward monotonic trend (a two-tailed test) at the $\alpha$ level of significance, $H_{0}$ is rejected if the absolute value of $Z$ is greater than $Z_{1-\alpha / 2}$, which is obtained from the standard normal cumulative distribution tables.

\subsection{Sen's slopes of trend}

Sen's nonparametric method is used to estimate the true slope of an existing trend (such as change per month), and the trend $f(t)$ is assumed to be linear:

$f(t)=Q t+B$

where $Q$ is the slope, and $B$ is a constant. The slopes of all data value pairs are calculated using Eq. (7), for $j>k$, to obtain the slope estimate $Q$ as the median of $Q_{i}$ values:

$Q_{i}=\frac{x_{j}-x_{k}}{j-k}$

\section{Results and discussion}

\subsection{Temporal variability of drought indices}

Figure 6 shows the mean monthly hyetograph (Fig. 6i) of the 187 series in the study area (Fig. 1b) between 1998 and 2015. It also shows the SPI-1, SPI-3, SPI-6, SPI-9, SPI-12, SPI-18, SPI-24 and SPI-48 indices calculated from the time series of the monthly mean precipitation of the study area, divided into groups that characterize the droughts as short-, medium- and long-term droughts, i.e., the SPI-1, SPI-3 and SPI-6 indices are related to short-term drought analyses (Fig. 6a-c), the SPI-9 and SPI-12 indices are related to medium-term drought analyses (Fig. 6d-e), and the SPI-18, SPI-24 and SPI-48 indices are related to long-term drought analyses (Fig. 6f-h).

Based on Fig. 6, the shorter the interval of the drought analysis, the greater the frequency of variation of SPI values between negative and positive values, breaking the continuity of an event with negative or positive SPI value. In addition, there is substantial similarity among the short-, medium- and long-term series: there is a slight difference in the SPI values, but the same behavior of continuity of dry and wet events is maintained throughout the series.

Figure 7 shows the occurrence percentages of drought and wet events for each SPI studied, to obtain a more detailed classification of the drought conditions found for the monthly mean precipitation (Fig. 6i) in the study region. This figure is important because it provides a means to evaluate in an integrated way the frequency of each type of drought or wet event for each SPI in the region as a whole throughout the time series, disregarding local peculiarities. Thus, when evaluating different SPIs, it can be seen from Fig. 7 that for SPI-6, which is commonly associated with agricultural droughts, the sum of the percentages of the occurrence of mild $(38.9 \%)$, moderate $(10 \%)$, severe $(4.3 \%)$ and extreme $(0.9 \%)$ drought events resulted in more than $50 \%$ of all possible events, indicating a predominance of drought events based on the monthly average rainfall series over the study area (Fig. 6). On the other hand, when evaluating the behavior of the different types of events and their frequencies, it can be seen from Fig. 7, for example, that the mild drought event (yellow bar) represents approximately $40 \%$ of the possible events when SPI-1 is analyzed, but when SPI-48 is analyzed, such a percentage decreases to approximately $20 \%$. This joint analysis of event frequency for each evaluated SPI is important to obtain a more refined characterization of the behavior of the region regarding different types of droughts, whether short-, medium- or long-term.

The short-term analysis shows that there was a greater occurrence of drought events than wet events, surpassing 
(a) SPI-1

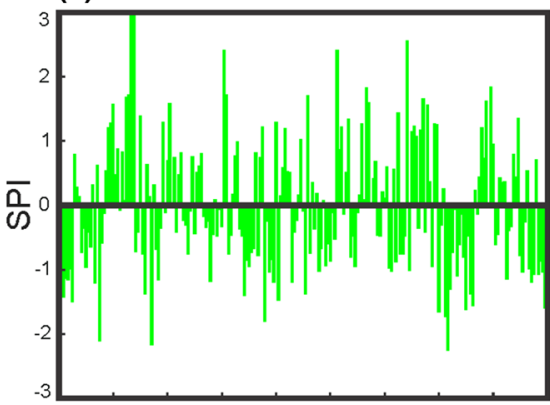

(b) SPI-3

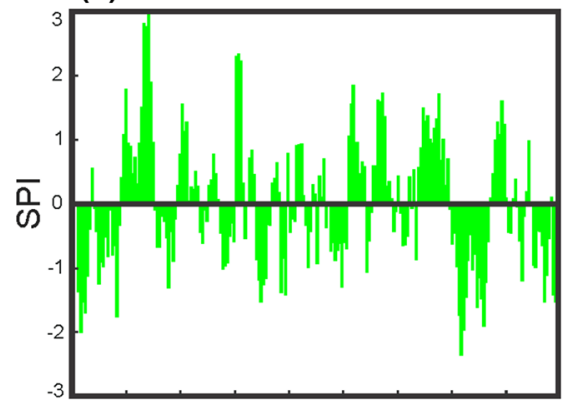

(c) SPI-6

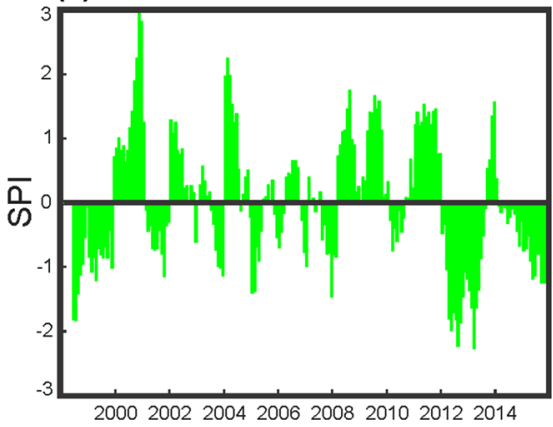

(i) Monthly hyetograph

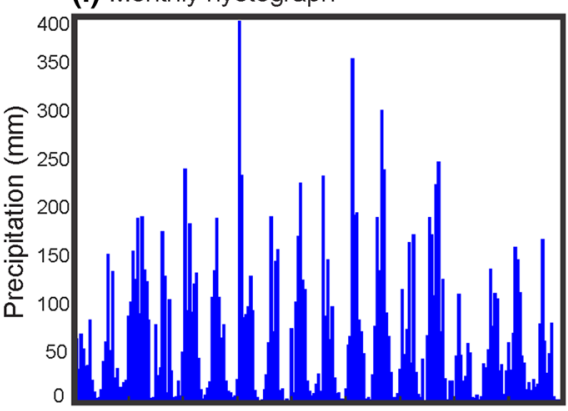

(d) SPI-9

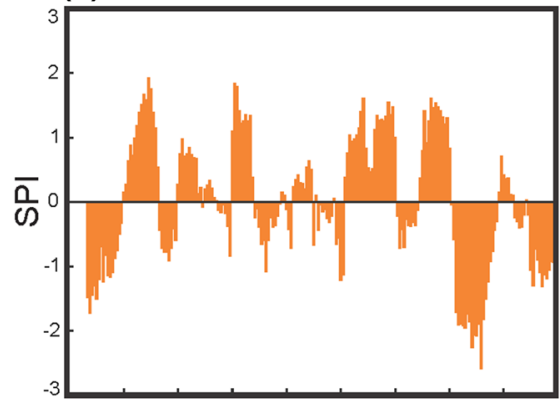

(e) SPI-12

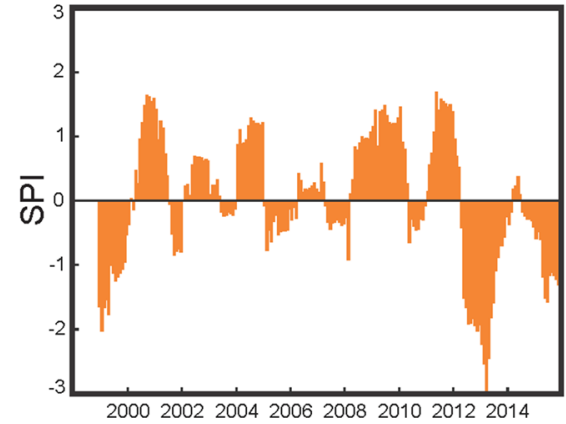

(f) SPI-18

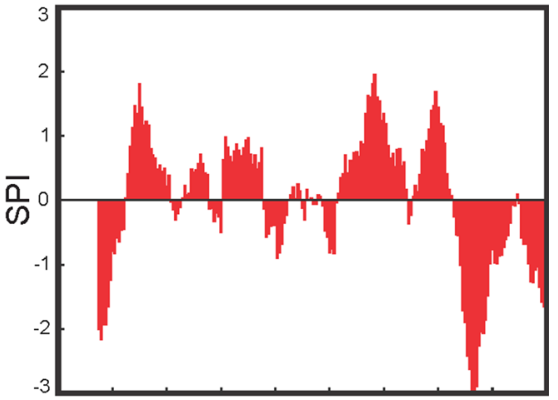

(g) SPI-24

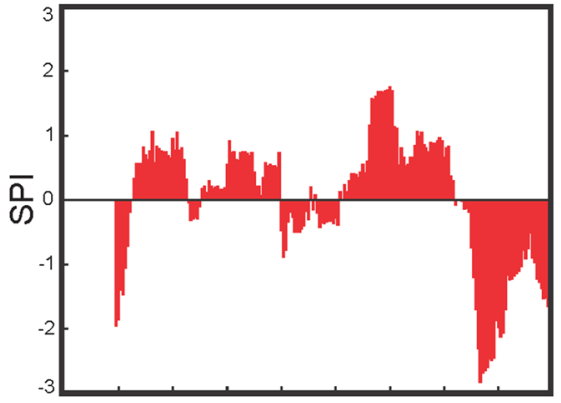

(h) SPI-48

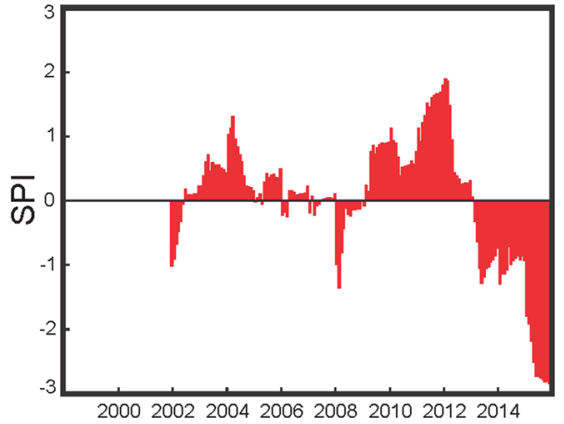

Fig. 6 Short-term drought analysis for a SPI-1, b SPI-3 and c SPI-6; medium-term drought analysis for d SPI-9 and e SPI-12; and long-term drought analysis for $\mathbf{f}$ SPI-18, $\mathbf{g}$ SPI-24 and h SPI-48, based on $\mathbf{i}$ the mean monthly hyetograph for the study area (1998-2015)

Fig. 7 Occurrence percentage for each type of drought and wet event for each SPI based on the mean monthly hyetograph for the study area (1998-2015)

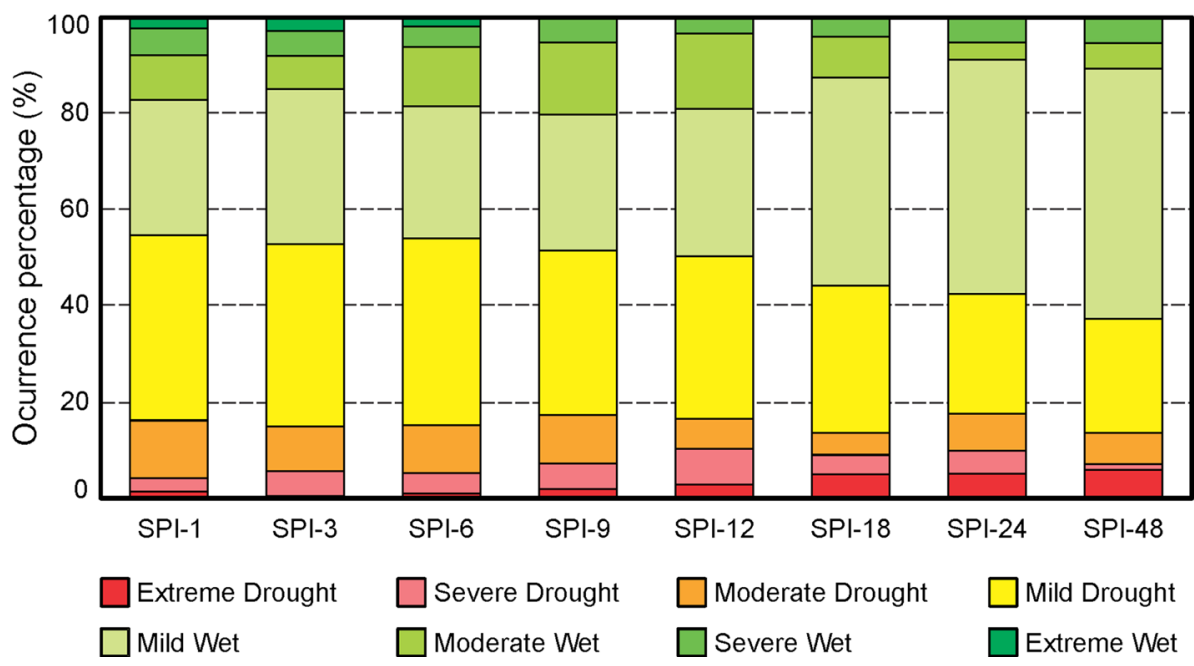


$55 \%$ of the total possible value. The medium-term analysis reveals that there was a greater balance between the number of drought and wet events, while there was a lower occurrence of drought events than wet events within all the intervals analyzed for the long-term analysis.

An increase in the interval of the drought analysis is related to a reduction in the percentage of drought events, reaching approximately $35 \%$ of the total possible value for SPI-48, for example. However, as the analysis interval increases (from short- to long-term), the percentage of severe and extreme drought events increases. The occurrence of extreme drought events, for example, changes from a basically null percentage in a short-term analysis to values that reach almost $6 \%$ of the total possible value in long-term analyses. This result means that, in the analysis of SPI-48, with 169 events calculated for the time series (216 - 47), almost 10 events were characterized as extreme drought events. The number of drought events decreased, but they became more severe as the analysis interval increased. Extreme and severe wet events basically remained constant for all SPIs analyzed, but the analysis of the moderate wet events, for example, showed a considerable increase of occurrence percentage of this type of event in the medium-term analyses, SPI-9 and SPI-12, whereas the mild wet events increased considerably as the drought analysis interval increased.

\subsection{Spatial analyses of drought indices}

Figures 6 and 7 were designed based on a mean time series in the study area; however, Fig. 8 shows a spatial analysis, for which each time series of each SPI (SPI-1, SPI-3, SPI6, SPI-9, SPI-12, SPI-18, SPI-24 and SPI-48) of each one of the 187 grids was calculated. Then, the respective occurrence percentages of each drought event (mild, moderate, severe and extreme) were characterized. Figure 8 is of great value because while Fig. 7 shows, for example, that the percentage of extreme drought event was approximately $6 \%$, when SPI-48 is analyzed, Fig. 8 shows where such events occur. More specifically, Fig. 8 is of utmost importance for this type of analysis not only because it couples the information of 187 figures analogous to Fig. 7, as there are 187 grid points and precipitation time series (Fig. 1), but also because it spatializes the obtained results. Although Fig. 7 provides important information and characteristics of the region as a whole, from Fig. 8, it is possible to further detail the behavior of each region of the study area regarding the frequency and type of the drought events, which are valuable information for regions with diverse rainfall regimes. In this case, it is important to highlight that as the focus of this study is to evaluate drought conditions, only the drought events are shown in Fig. 8, and for this reason, 32 maps are presented, referring to the eight analyzed SPI and the four types of drought events, i.e., extreme, severe, moderate and mild.

According to the occurrence percentages of each type of drought event for each SPI index analyzed throughout the entire time series shown in Fig. 8, for SPI-1, for example, in the majority of the state of Paraíba, approximately $30 \%$ of the events that occurred between 1998 and 2015 were mild drought events. This result means that within 216 months (1998-2015), approximately 60 months showed SPI values higher than or equal to -1.0 and lower than or equal to 0.0 , i.e., a value of $30 \%$. The analysis is analogous for the other classifications and SPI indices. For SPI-48, especially in the region of Borborema, there were high percentages of extreme drought events, totaling values close to $8 \%$. For this SPI, of the 169 months $(216-47)$, more than 10 events showed SPI values lower than -2.0 .

For a complete characterization of the drought events that have affected the region of the state of Paraíba, the type of drought was characterized according to the classification proposed by Santos et al. (2017), i.e., short-, medium- and long-term drought, depending on the type of drought event (extreme, severe, moderate and mild) analyzed. Using the global cumulative probability shown in the normal distribution curve of SPI (Fig. 5) as a boundary percentage to determine which region had been affected by drought, the drought affecting a given region was characterized according to the analysis interval. For extreme drought events, for example, any grid that reached the occurrence percentage of this type of event of more than $2 \%$ throughout the time series would reveal that the occurrence percentage would be higher than what was expected according to the normal distribution of the SPI curve. Therefore, an analogous idea was followed for all types of drought events and for each SPI analyzed, resulting in the spatial distributions shown in Fig. 9.

To characterize the drought events, an alternative classification was performed, in which the drought type (short-, medium-, and long-term) was categorized according to the analyzed drought event type (extreme, severe, moderate, and mild). The global cumulative probability presented in Fig. 5 was used as the limit percentage to determine whether a location was affected by some type of drought. For example, for mild drought events in an SPI-1, SPI-3, or SPI-6 analysis, any region with an occurrence percentage over $34 \%$ would be affected by short-term droughts, whereas in an either SPI-9 or SPI-12 analysis, the region would be affected by a medium-term drought.

Figure 9 simultaneously reveals two pieces of information, as it shows the spatial distribution of the areas affected by short-, medium- and long-term droughts for all types of drought events (mild, moderate, severe and extreme). Mild drought events tend to affect most areas of Paraíba when short-term droughts are analyzed, while the 

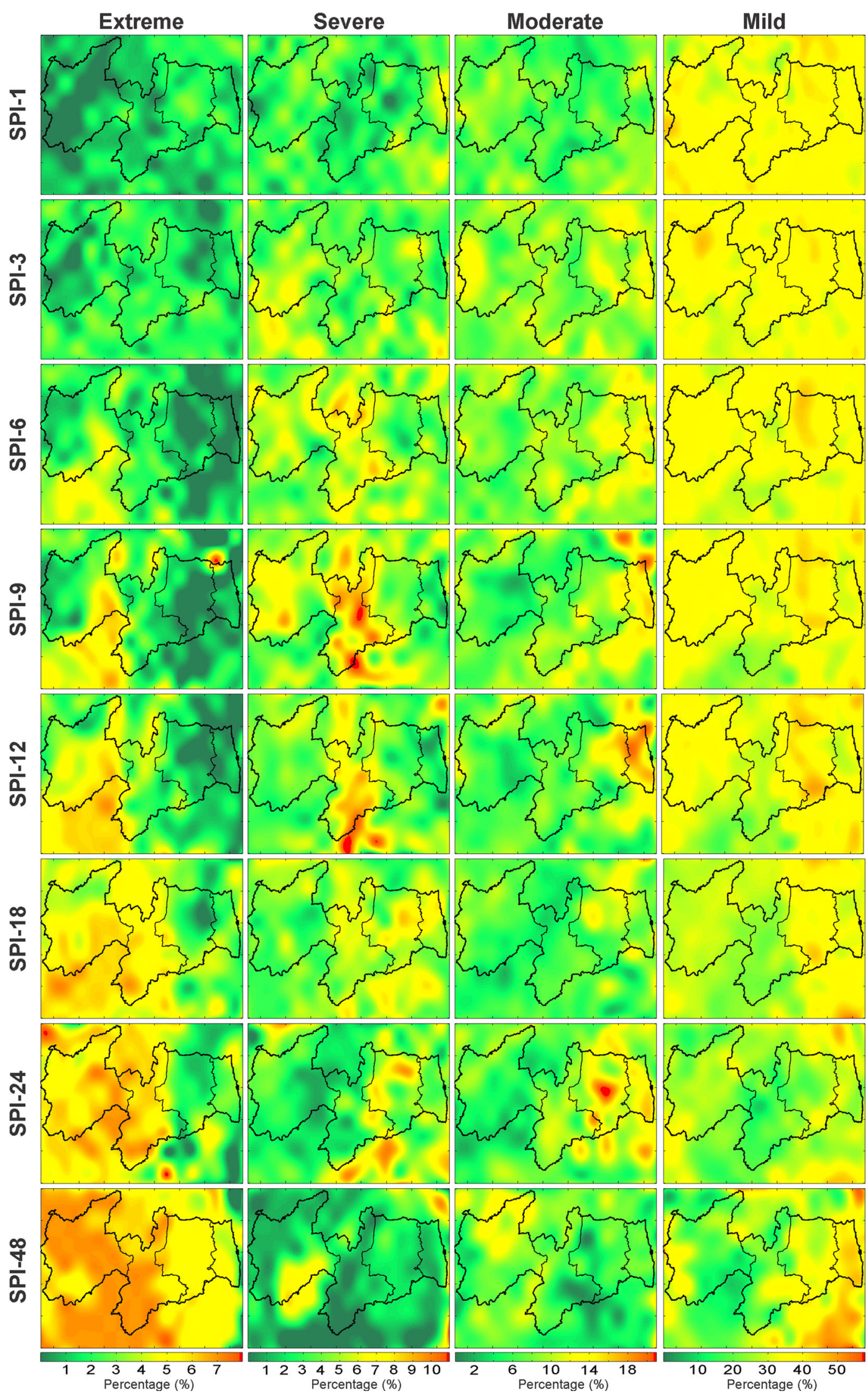
4Fig. 8 Occurrence percentages of each drought event (mild, moderate, severe and extreme) for each SPI time series

coastal region and the Sertão are affected when mediumterm droughts are analyzed, and basically, the coastline is affected by such events when long-term droughts are analyzed. In moderate drought events, the coastal region is the most affected area for short-, medium- and long-term droughts, and for this type of drought event, the smallest percentages of the areas affected by droughts are found compared with other types of drought events, i.e., mild, severe and extreme droughts. For the severe drought events, the SPI-6, SPI-9 and SPI-18 indices are those that most affected the state of Paraíba, and the regions of Borborema and Agreste are the most affected. Finally, regarding extreme drought events, Paraíba is considerably affected when the long-term droughts are analyzed. For SPI-48, for example, the entire state is affected by extreme drought events in such a time scale of 48 months, except for a small southern region in the coastal area.

Figure 10 shows the percentage of the area affected by each SPI regarding a given type of drought event. These results show that the long-term droughts (SPI-18, SPI-24 and SPI-48) affect Paraíba more significantly, as more than $75 \%$ of the region is affected in extreme drought events. The medium-term droughts (SPI-9 and SPI-12) basically show the same behavior and affect $40-60 \%$ of the study region for all types of drought events, except for the moderate drought events. On the other hand, the short-term droughts affect the state of Paraíba more significantly when the mild drought events are analyzed. Once more, we can see that as the drought analysis interval increases, i.e., from short- to long-term drought, the more severe are the drought events affecting the region.

Following a methodology analogous to that used by Santos et al. (2017), a new classification of drought severity is proposed. With global cumulative probabilities shown in the SPI distribution curve (Fig. 5), the severity of the drought affecting a given region for each one of the SPIs analyzed is characterized. For example, the probability of an extreme drought event occurring is approximately $2 \%$, while the probability of a mild drought event occurring is somewhat greater than $34 \%$. Taking this into account, the weight attributed to the occurrence of an extreme drought event is much higher than the weight of a mild drought event. Based on these probabilities, a new drought classification can be developed. For example, the drought severity $(D S)$ index for each region where the four types of drought events occurred (extreme, severe, moderate and mild drought) is equal to 0.805 , as the result of the sum of $1 / 2.28+1 / 4.41+1 / 9.18+1 / 34.13$, while $D S$ would be equal to 0.109 for a region where there was only a moderate drought event during the period analyzed (1/ 9.18). Table 1 shows the complete classification for all types of combinations of drought occurrences, which receive classifications from 0 to 15 .

Table 1 shows that the classification 0 represents a region that is not affected by any type of drought event, while the classification 15 represents a region that is affected by all types of drought events. When there is low global cumulative probability of extreme drought events, the weight attributed to this type of event is higher. Therefore, the regions that are affected only by extreme drought events, regardless of the drought analysis interval, are classified as high-severity drought areas. Figure 11 shows the spatial distribution of the drought severity classification of the state of Paraíba for each SPI calculated based on the TRMM between 1998 and 2015 .

In summary, Fig. 11 represents the set of information provided by Fig. 9, in which, for a given SPI, a classification value (from 0 to 15 ) of drought severity is attributed based on the types of drought events that affected a given region. For example, Fig. 11a represents the set of information provided in the first line of Fig. 9 (i.e., Figures 9ad) combined with the classification shown in Table 1. For short-term droughts, i.e., SPI-1, SPI-3 and SPI-6 (Fig. 11ac), there are many regions that show low classification values of drought severity. The comparison of this piece of information with that illustrated in Fig. 9 shows that, although the majority of the state of Paraíba was affected by mild drought events, the state was not affected by other types of more severe drought events. Therefore, the severity classification was lower (Table 1). For mediumterm droughts (Fig. 11d-e), there is a considerable increase in the severity classification of droughts that affected the region, especially due to extreme and severe drought events, which affected primarily the regions of Sertão and Borborema. For long-term droughts (Fig. 11f-h), the greatest drought severities are found, and they occurred especially due to extreme drought events that affected the region. In the classification of drought severity, if the drought analysis interval is increased (from short- to longterm drought), the level of severity $(D S)$ in the entire state increases. Special attention may be drawn to the coastal region, as the classification values of $D S$ for SPI-1 to SPI12 were frequently lower than 5 , whereas there were high values of $D S$ classification for SPI-18 to SPI-48 (long-term droughts) in several regions.

\subsection{Mann-Kendall test and Sen's slopes of trend}

The Mann-Kendall and Sen's tests were applied to each one of the 187 time series of SPI-1, SPI-3, SPI-6, SPI-9, SPI-12, SPI-18, SPI-24 and SPI-48 to analyze the trends of 

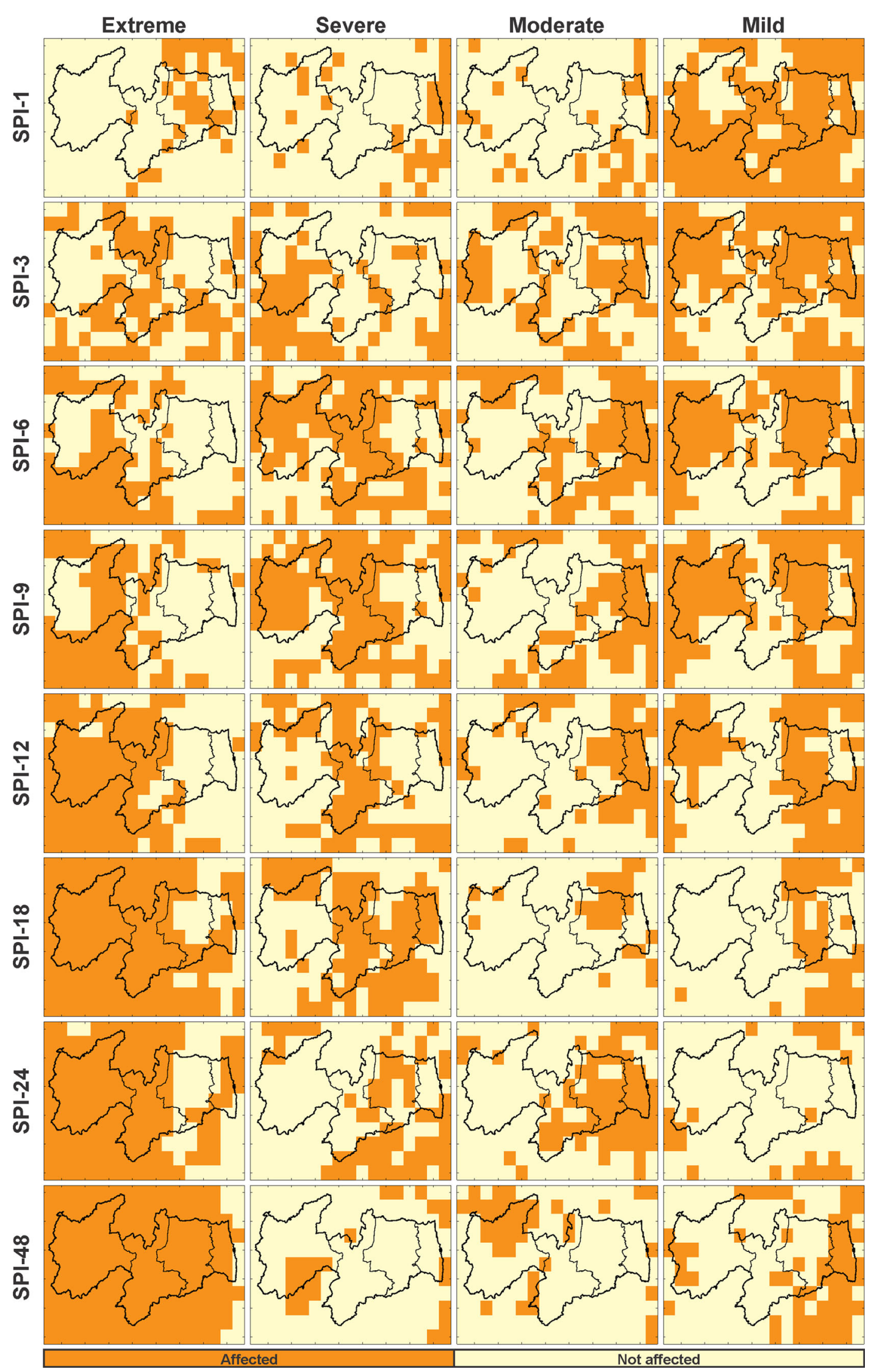
4Fig. 9 Spatial grid distributions of the areas affected by droughts (SPI-1, SPI-3, SPI-6, SPI-9, SPI-12, SPI-18, SPI-24 and SPI-48) for extreme, severe, moderate and mild drought events

the SPI indices, using a Matlab script developed by Burkey (2006). In this study, as noted previously, a significance level of 0.01 was used to obtain $99 \%$ confidence in the trend results of each short-, medium- and long-term time series in the study area. Figure 12 shows the spatial distributions of the SPI series that did or did not show a trend at the significance level of 0.01 , while Fig. 13 shows a spatial distribution of the real slope of these series (Sen's slope).
In all the drought analysis intervals, most parts of the Agreste and Mata mesoregions show a trend at the significance level of 0.01 . As the drought interval increases, that is, as the analysis interval changes from short- to longterm drought, the majority of the state of Paraíba shows this trend. For instance, the analysis of the long-term droughts (SPI-18, SPI-24 and SPI-48) reveals that the entire state shows a trend, except for the region of Sertão.

The joint analysis of the results and the observation of the points and regions that showed a trend in the MannKendall test reveal that the majority of the state of Paraíba shows a negative trend. This result indicates that the SPI values, to which Sen's test was applied, tend to be lower; thus, the intensity and severity of drought events tend to be
Fig. 10 Percentage of the areas affected by drought events for each SPI
Table 1 Classification for the drought severity $(D S)$ based on cumulative probability for each drought event

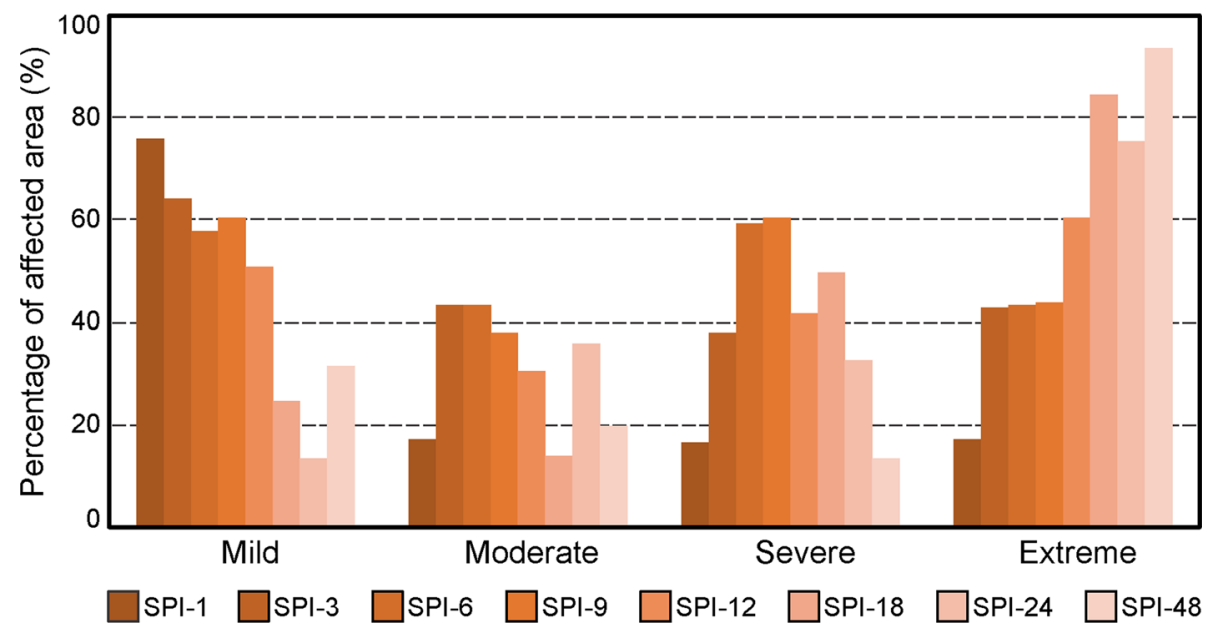

\begin{tabular}{|c|c|c|c|c|c|}
\hline \multicolumn{4}{|c|}{ Cumulative probability for each drought event } & \multirow[t]{2}{*}{$D S$} & \multirow[t]{2}{*}{ Classification } \\
\hline $2.28 \%$ & $4.41 \%$ & $9.18 \%$ & $34.13 \%$ & & \\
\hline & & & & 0.000 & 0 \\
\hline & & & Mild & 0.029 & 1 \\
\hline & & Moderate & & 0.109 & 2 \\
\hline & & Moderate & Mild & 0.138 & 3 \\
\hline & Severe & & & 0.227 & 4 \\
\hline & Severe & & Mild & 0.256 & 5 \\
\hline & Severe & Moderate & & 0.336 & 6 \\
\hline & Severe & Moderate & Mild & 0.365 & 7 \\
\hline Extreme & & & & 0.440 & 8 \\
\hline Extreme & & & Mild & 0.469 & 9 \\
\hline Extreme & & Moderate & & 0.548 & 10 \\
\hline Extreme & & Moderate & Mild & 0.578 & 11 \\
\hline Extreme & Severe & & & 0.667 & 12 \\
\hline Extreme & Severe & & Mild & 0.696 & 13 \\
\hline Extreme & Severe & Moderate & & 0.775 & 14 \\
\hline Extreme & Severe & Moderate & Mild & 0.805 & 15 \\
\hline
\end{tabular}


(a) SPI-1

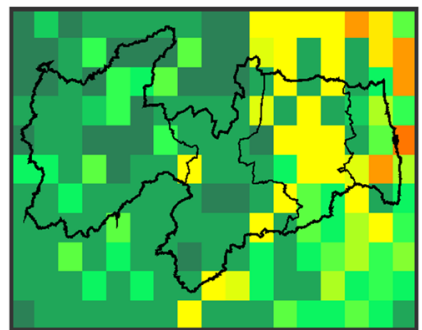

(b) SPI-3

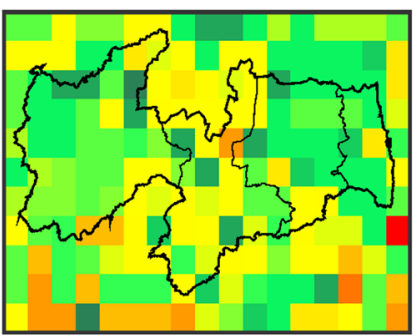

(e) SPI-12

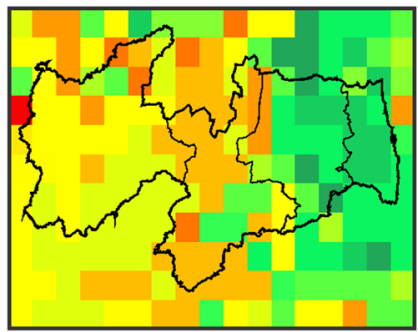

(f) $\mathrm{SPI}-18$

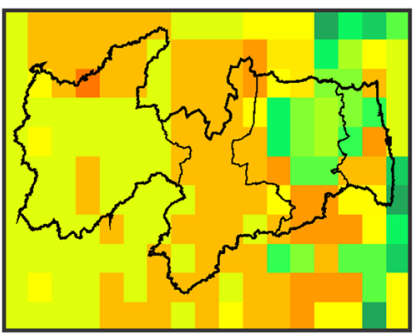

(c) SPI-6

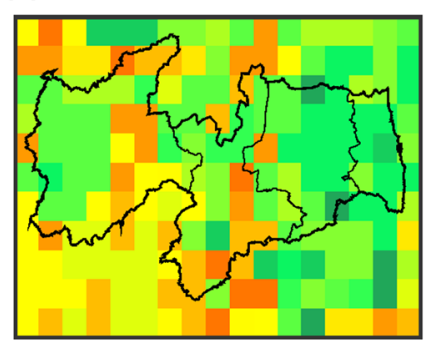

(d) SPI-9

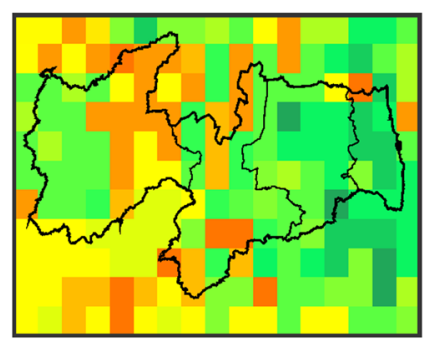

(g) SPI-24

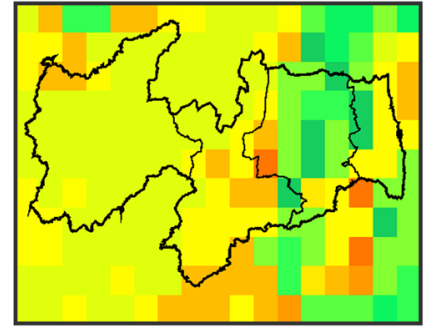

(h) SPI-48

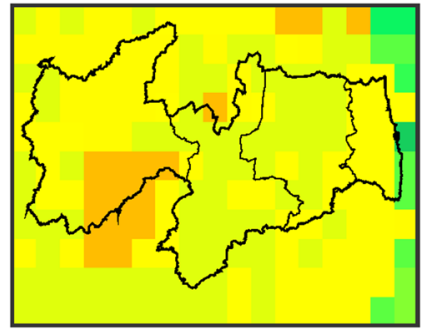

8

\section{Drought Severity $(D S)$}

Fig. 11 Spatial grid distributions of the classification of the drought severity (DS) for each SPI over Paraíba state (1998-2015)

(a) SPI-1

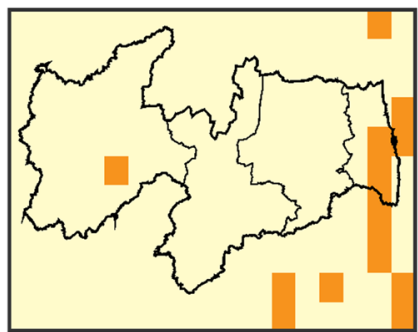

(e) SPI-12

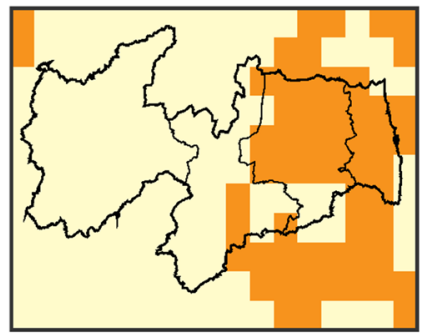

(f) SPI-18

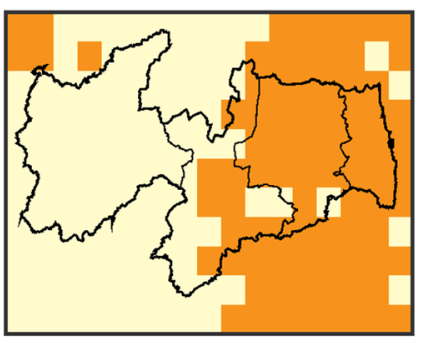

Trend

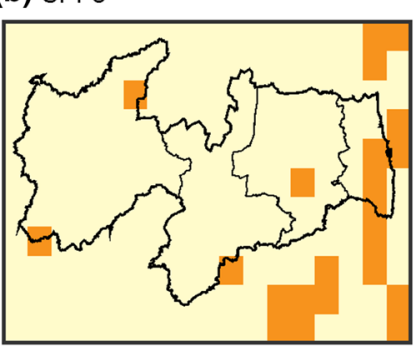

(c) SPI-6

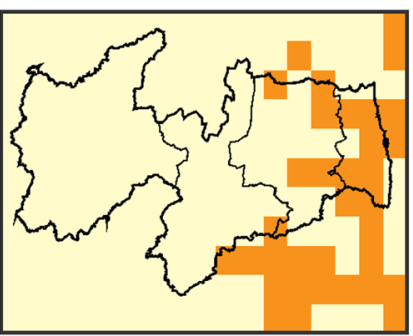

(d) SPI-9

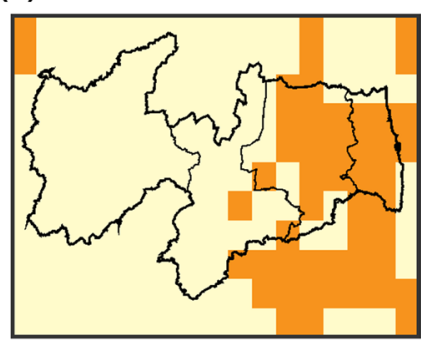

(g) SPI-24

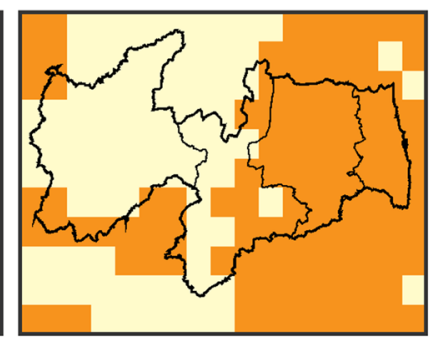

(h) $\mathrm{SPI}-48$

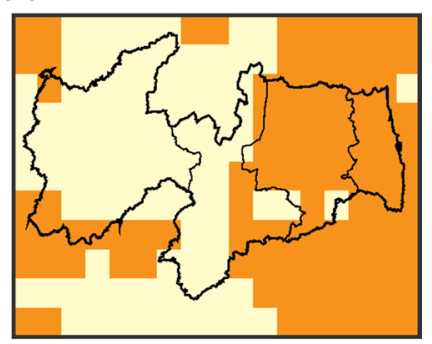

No trend

Fig. 12 Spatial grid distributions of the time series with or without a trend for each SPI over Paraíba state (1998-2015) at a significance level of 0.01

higher. Sen's test also shows that the negative slopes of trend of each of the 187 series of the TRMM grid tend to be pronounced in the coastal region and less pronounced in the Sertão mesoregion. Borborema and Agreste are the mesoregions that show mean negative slope compared with the extremes of the state (coastline and Sertão). The application of Sen's test shows that, as the drought analysis interval changes from short- to long-term drought, the slope values tend to be more pronounced in any region of the state of Paraíba, and, therefore, the trend is that SPI values are increasingly smaller. 
(a) SPI-1

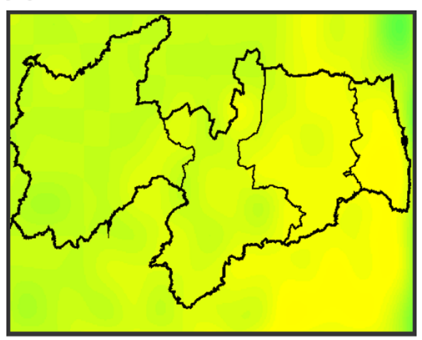

(b) SPI-3
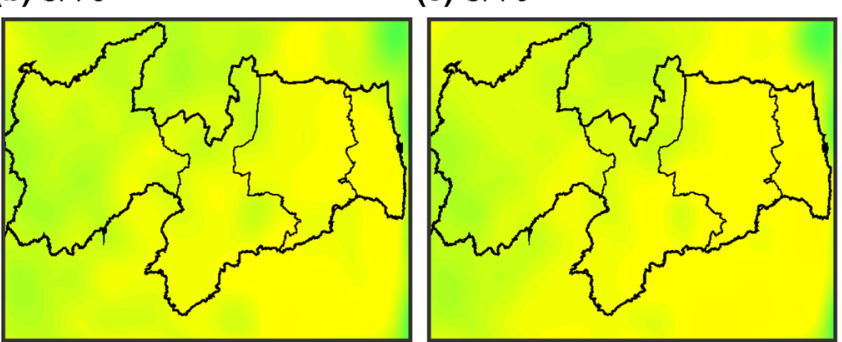

(d) SPI-9

(e) SPI-12

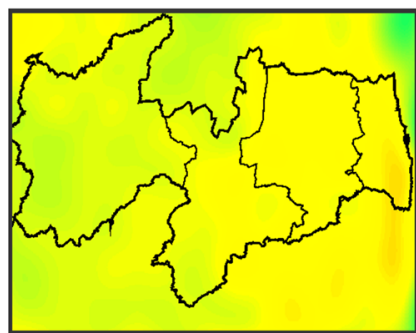

(f) $\mathrm{SPI}-18$

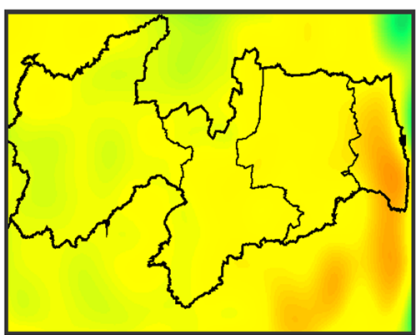

(g) SPI-24

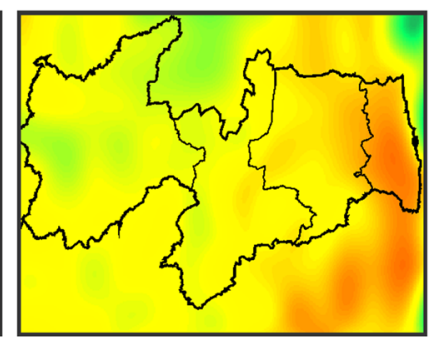

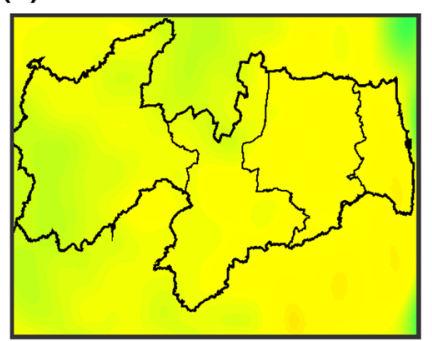

(h) SPI-48

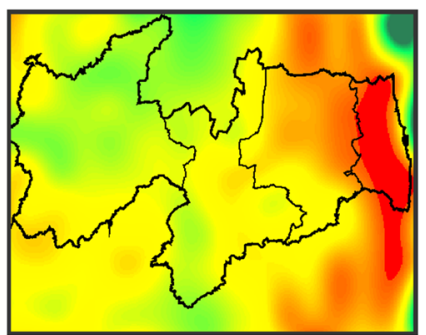

0.015

0.010

0.005

0.0

$-0.005$

$-0.010$

$-0.015$

Fig. 13 Spatial distributions of Sen's slope for each SPI across Paraíba state (1998-2015)

\subsection{Drought risk analysis}

To summarize all drought information in one risk analysis classification, the information of each one of the SPI indices and of the Mann-Kendall and Sen's tests are gathered. Based on the drought severity classification, on the information about which series show a trend or not and on the slope of the trend line of each one of the series, a classification is proposed to analyze the current situation of a given region regarding drought, as well as its trend at the significance level of 0.01 , for any SPI.

In this case, there are three possible trends: positive, negative and no trend, which are represented by the colors green, red and orange, respectively. In addition, the classification from 0 to 15 (Table 1 ) provides the information on drought severity. For example, 0 shows that the region was not affected by any type of drought event, while 15 indicates that the region was affected by all four types of drought events. Therefore, the classification 15 red indicates that a given region was affected by all types of drought events and that the SPI series shows a negative trend, which means that the SPI values are increasingly lower, intensifying the number of drought events. On the other hand, the classification 15 orange shows that, although the region was affected by all types of drought events, there was no trend at the significance level of 0.01 . The classification 8 green means that the region was affected only by the extreme drought events, but its SPI series showed a positive trend. With this classification, it is possible to know exactly which types of drought events did or did not affect the region and what are the trends of the SPI series analyzed and, therefore, the situation of drought risk analysis. Figure 14 shows the spatial distribution of such drought risk analysis for each SPI over the state of Paraíba for the period analyzed, using the spline spatial interpolation method; other interpolation techniques could also be used (e.g., indicator kriging and disjunctive kriging), as used by de Brito Neto et al. (2016), but for the interpolation of the present data, the spline method showed to be adequate, as suggested by Huang et al. (2014).

\section{(a) Risk of short-term droughts}

The analysis of Fig. 14a-c shows that, for short-term droughts (SPI-1, SPI-3 and SPI-6), the coastal area was the region most significantly affected by this type of drought, showing a negative trend of the SPI values. On the other hand, the Agreste, Borborema and Sertão regions of Paraíba basically did not show trends in the SPI values, and the low values in the classification indicate that these regions were not severely and simultaneously affected by extreme, severe, moderate and mild drought events.

(b) Risk of medium-term droughts

The analysis of the behavior of medium-term droughts (SPI-9 and SPI-12), based on Fig. 14d, e, shows that most of the coastal area and the Agreste of Paraíba were affected by these drought events, which were predominantly moderate and mild. Furthermore, according to the series trend 
(a) SPI-1

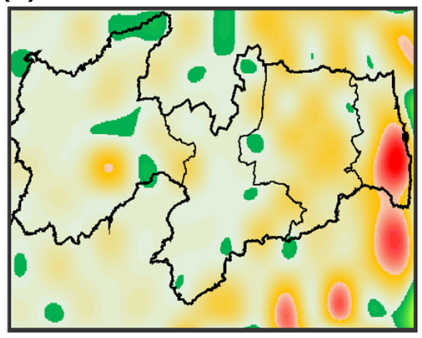

(b) SPI-3

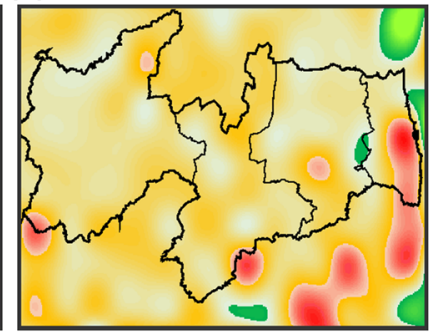

(c) $\mathrm{SPI}-6$

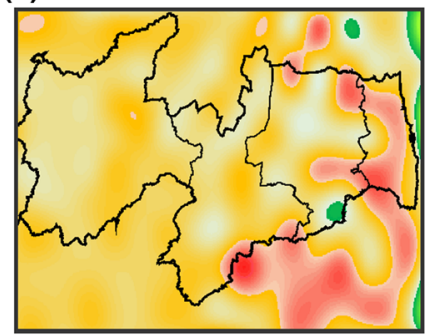

(d) SPI-9

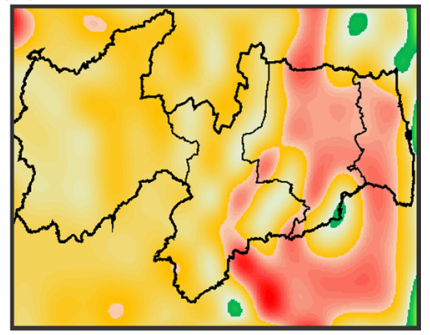

(e) SPI-12

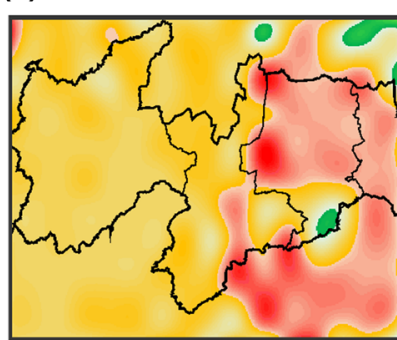

(f) $\mathrm{SPI}-18$

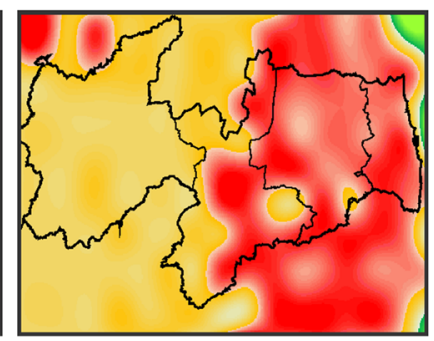

(g) SPI-24

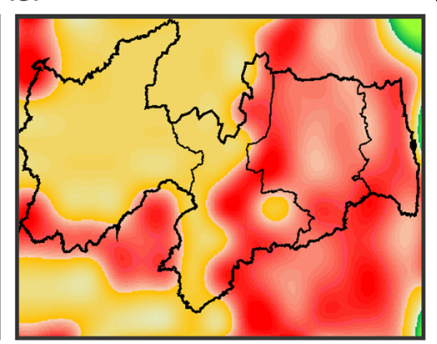

(h) SPI-48

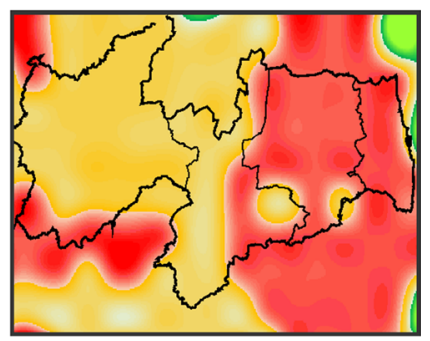

\section{Drought severity}
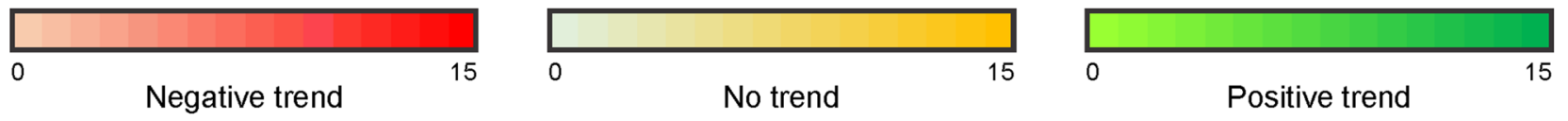

Fig. 14 Spatial distributions of the drought risk analysis for each SPI across Paraíba state, in which green represents positive trends, orange no trends and red negative trends (1998-2015)

analysis, the SPI values tend to be increasingly lower, which worsens the situation in these regions. The Sertão and Borborema mesoregions were also affected by medium-term droughts; however, the majority of these regions did not show a trend at the significance level of 0.01 , which indicates that the SPI-9 and SPI-12 values tend to stay constant in these regions.

\section{(c) Risk of long-term droughts}

Based on Fig. 14f, g, h, the analysis of the long-term droughts (SPI-18, SPI-24 and SPI-48) shows that for such droughts, the majority of the coastal region and the Agreste was affected by these droughts, and according to the trend analysis, the SPI values tend to fall more and more. Unlike what occurred in the medium-term drought analysis, some regions of Sertão and Borborema were not only significantly affected by these types of droughts but also showed a negative trend in their time series. However, it is worth noting that most of these regions located in inland Paraíba showed the same behavior as the analysis of the mediumterm droughts, accepting the null hypothesis of the MannKendall test and admitting that the series did not show downward or upward monotonic trends.

\section{Conclusions}

This paper dealt with the analysis of drought trends in Paraíba state using TRMM data and the application of the MannKendall and Sen tests based on the SPI indices. The main purposes were to analyze the severity of droughts that affected Paraíba state and to statistically evaluate whether there were monotonic upward or downward trends of SPI at different time scales during the last years. Thus, the study was focused on the analysis of the changes that have occurred since 1998; therefore, there was no need to divide the time series to guarantee the monotonic trend and, thus, the MannKendall test, the Sen test and the TRMM data were suitable for such a purpose. In addition, several indices could be used for drought analysis, but the World Meteorological Organization recommends the SPI for monitoring of dry spells because it requires only monthly precipitation data, can be compared across regions with markedly different climates and can determine the rarity of an ongoing drought. Thus, a high-density network of daily precipitation series (187 time series) from the TRMM mission across Paraíba state was used for a period of 18 years (1998-2015), corresponding from the same product, 3B42 (V7), which also ensured the homogeneity of the data used.

For the SPI analysis, a drought severity analysis classification $(D S)$ based on the global cumulative probabilities 
of the SPI curve was proposed. According to this classification, for short-term droughts, it was noted that many regions present low values of drought severity classification, among which the Borborema region presented the highest drought severity classifications among the studied mesoregions. For medium-term droughts, there was a considerable increase in the severity classification of the droughts that affected Paraíba state, mainly in the Sertão and Borborema regions. For long-term droughts, the highest drought severity that was found affected the coastal area considerably. From the classification of drought severity, it is noted that by increasing the drought analysis interval (from short- to long-term), the degree of severity $(D S)$ over the entire state increases. In addition, special attention can be given to the coastal area when analyzing long-term droughts and to the Borborema region when analyzing short- and medium-term droughts.

Analyzing the results of the Mann-Kendall test, it was noted that in all the different intervals of drought analysis, most of the Agreste and Mata mesoregions of Paraíba presented trends at a significance level of 0.01 . According to the Sen test, a great part of Paraíba state has negative trends, which tend to be more accentuated in the coastal area and less pronounced in the Sertão region. In addition, it was observed that as the analysis interval of the drought changes from short- to long-term, not only does most of Paraíba state begin to show a trend but also the trend line slope values tend to be more negatively accentuated in any region of Paraíba state.

Finally, an innovative approach for geospatial classification of drought risk analysis was proposed, based on the drought severity classification, on the trend line slopes for each time series, and on whether the time series presented a trend or not at a significance level of 0.01 , as for (a) risk of short-term droughts: the coastal area was the region most significantly affected, and the SPI values showed a negative trend, but the Agreste, Borborema and Sertão regions of the state of Paraíba basically did not show trends, and the low classification values indicated that these regions were not severely and simultaneously affected by extreme, severe, moderate and mild drought events; (b) risk of medium-term droughts: the majority of the coastal area and the Agreste region of the state of Paraíba was affected by predominantly moderate and mild drought events, and the SPI values tend to decrease, which worsens the situation for these regions. Although the Sertão and Borborema regions are affected by medium-term droughts, they basically did not show a trend; and (c) risk of long-term droughts: the majority of the coastal area and Agreste was also severely affected by long-term droughts, and the SPI values tend to decrease more and more. In addition, some regions in the Sertão and Borborema were not only severely affected but also showed a negative trend. On the other hand, most regions located within the limits of the state of Paraíba did not show downward or upward monotonic trends. In this way, the proposed classification is shown to be useful because it allows identifying which types of drought events affected a region and whether a trend exists and provides the index variation rate for each drought duration analysis (short-, medium- and long-term).

Acknowledgements The financial support provided by the National Council for Scientific and Technological Development, Brazil CNPq (Grant No. 304213/2017-9, 304540/2017-0 and 408631/20163) and the data from the Tropical Rainfall Measuring Mission (TRMM) are gratefully acknowledged. This study was also financed in part by the Brazilian Agency for the Improvement of Higher Education (Coordenação de Aperfeiçoamento de Pessoal de Nível Superior - CAPES) - Fund Code 001, and Universidade Federal da Paraíba.

Open Access This article is distributed under the terms of the Creative Commons Attribution 4.0 International License (http://creative commons.org/licenses/by/4.0/), which permits unrestricted use, distribution, and reproduction in any medium, provided you give appropriate credit to the original author(s) and the source, provide a link to the Creative Commons license, and indicate if changes were made.

\section{References}

Achugbu IC, Anugwo SC (2016) Drought trend analysis in Kano using standardized precipitation index. FUOYE J Eng Technol 1(1): 105-110

Ashraf M, Routray JK (2015) Spatio-temporal characteristics of precipitation and drought in Balochistan Province, Pakistan. Nat Hazards 77:229-254. https://doi.org/10.1007/s11069-015-1593-

Burkey J (2006) A non-parametric monotonic trend test computing Mann-Kendall Tau, Tau-b, and Sen's Slope written in Mathworks-MATLAB implemented using matrix rotations. King County, Department of Natural Resources and Parks, Science and Technical Services section. Seattle, Washington. USA. www.mathworks.com/matlabcentral/fileexchange/authors/23983

Cancelliere A, Di Mauro G, Bonaccorso B, Rossi G (2007) Drought forecasting using the Standardized Precipitation Index. Water Resour Manag 21:801-819. https://doi.org/10.1007/s11269-0069062-y

de Brito Neto RT, Santos CAG, Mulligan K, Barbato L (2016) Spatial and temporal water-level variations in the Texas portion of the Ogallala Aquifer. Nat Hazards 80:351-365. https://doi.org/10. 1007/s11069-015-1971-8

Faiz MA, Liu D, Fu Q, Uzair M, Khan MI, Baig F, Li T, Cui S (2018) Stream flow variability and drought severity in the Songhua River Basin, Northeast China. Stoch Environ Res Risk Assess 32:1225-1242. https://doi.org/10.1007/s00477-017-1463-3

Farias AA, Souza JTA, Sousa FAS (2014) Identificação e análise de secas severas e extremas no município de Taperoá-PB. Revista Brasileira de Geografia Física 7(5):818-826 (Special issue VIWMCRHPE)

Gilbert RO (1987) Statistical method for environmental pollution monitoring, Chapter 16.4 Mann-Kendall Test, pp 208-217, and Appendix A, Table A.18 Probabilities for Mann-Kendall nonparametric test for trend, $\mathrm{p} 272$. Wiley, New York 
Heim RR (2002) A review of twentieth-century drought indices used in the United States. Bull Am Meteor Soc 83:1149-1165. https:// doi.org/10.1175/15200477(2002)083\%3c1149:AROTDI\%3e2.3. $\mathrm{CO} ; 2$

Huang C, Zheng X, Tait A, Dai Y, Yang C, Chen Z, Li T, Wang Z (2014) On using smoothing spline and residual correction to fuse rain gauge observations and remote sensing data. J Hydrol 508:410-417. https://doi.org/10.1016/j.jhydrol.2013.11.022

Huffman GJ, Bolvin DT, Nelkin EJ, Wolff DB (2007) The TRMM multisatellite precipitation analysis (TMPA): quasi-global, multiyear, combined-sensor precipitation estimates at fine scales. J Hydrometeorol 8(1):38-55. https://doi.org/10.1175/JHM560.1

Kummerow C, Barnes W, Kozu T, Shiue J, Simpson J (1998) The tropical rainfall measuring mission (TRMM) sensor package. J Atmos Ocean Technol 15(3):809-817

Macedo MJH, Guedes RVS, Souza FAS, Santas FRC (2010) Analysis of the standardized precipitation index for the Paraíba state, Brazil. Ambiente Água 5(1):204-214. https://doi.org/10.4136/ ambi-agua. 130

Mansouri Daneshvar MR, Bagherzadeh A, Khosravi M (2013) Assessment of drought hazard impact on wheat cultivation using standardized precipitation index in Iran. Arab J Geosci 6(11):4463-4473. https://doi.org/10.1007/s12517-012-0695-2

Marengo JA, Torres RR, Alves LM (2017) Drought in Northeast Brazil-past, present, and future. Theor Appl Climatol 129(3-4):1189-1200. https://doi.org/10.1007/s00704-016-18408

Mathbout S, Lopez-Bustins JA, Martin-Vide J, Bech J, Rodrigo FS (2018) Spatial and temporal analysis of drought variability at several time scales in Syria during 1961-2012. Atmos Res. https://doi.org/10.1016/j.atmosres.2017.09.016

McKee TB, Doesken NJ, Kliest J (1993) The relationship of drought frequency and duration to time scales. American Meteorological Society, Boston, pp 179-184

Nicholson SE, Some B, McCollum J, Nelkin E, Klotter D, Berte Y, Diallo BM, Gaye I, Kpabeba G, Ndiaye O, Noukpozounkou JN, Tanu MM, Thiam A, Toure AA, Traore AK (2003) Validation of TRMM and other rainfall estimates with a high density gauge dataset for West Africa Part II: validation of TRMM rainfall products. J Appl Meteorol 42(10):1355-1368. https://doi.org/10. 1175/1520-0450(2003)042\%3c1355:votaor\%3e2.0.co;2

Nóbrega RS, de Souza EP, Sousa FAS (2008) Análise da utilização de dados do satélite TRMM em um modelo hidrológico semidistribuído na bacia do rio Jamari (RO). Revista Brasileira de Geografia Física Recife-PE 1:47-61

Palmer WC (1965) Meteorological drought. Research Paper no. 45, US Weather Bureau, Washington, DC, USA

Park SY, Sur C, Kim JS, Lee JH (2018) Evaluation of multi-sensor satellite data for monitoring different drought impacts. Stoch Environ Res Risk Assess. https://doi.org/10.1007/s00477-018$1537-\mathrm{x}$

Partal T, Kahya E (2006) Trend analysis in Turkish precipitation data. Hydrol Process 20:2011-2026. https://doi.org/10.1002/hyp.5993

Pereira G, Silva MES, Moraes EC, Cardozo FS (2013) Avaliação dos dados de precipitação estimados pelo satélite TRMM para o Brasil. Braz J Water Resour 18(3):139-148. https://doi.org/10. 21168/rbrh.v18n3.p139-148

Rossato L, Marengo JA, Angelis CF, Pires LBM, Mendiondo EM (2017) Impact of soil moisture over Palmer Drought Severity Index and its future projections in Brazil. Braz J Water Resour 22(36):1-16. https://doi.org/10.1590/2318-0331.0117160045

Salmi T, Määttä A, Anttila P, Ruoho-Airola T, Amnell T (2002) Detecting trends of annual values of atmospheric pollutants by the Mann-Kendall test and Sen's slope estimates-the Excel template application MAKESENS. Publications on Air Quality,
No. 31, Report code FMI-AQ-31. Finnish Meteorological Institute

Santos CAG, Brasil Neto RM, Passos JSA, Silva RM (2017) Drought assessment using a TRMM-derived Standardized Precipitation Index for the Upper São Francisco River basin, Brazil. Environ Monit Assess 189:250. https://doi.org/10.1007/s10661-0175948-9

Santos CAG, Brasil Neto RM, Silva RM, Passos JSA (2018) Integrated spatiotemporal trends using TRMM 3B42 data for the Upper São Francisco River basin, Brazil. Environ Monit Assess 190:175. https://doi.org/10.1007/s10661-018-6536-3

Silva RM, Santos CAG, Lima Silva VC, Silva LP (2013) Erosivity, surface runoff, and soil erosion estimation using GIS-coupled runoff-erosion model in the Mamuaba catchment, Brazil. Environ Monit Assess 185(11):8977-8990. https://doi.org/10. 1007/s10661-013-3228-x

Silva RM, Santos CAG, Moreira M, Corte-Real J, Silva VCL, Medeiros IC (2015) Rainfall and river flow trends using MannKendall and Sen's slope estimator statistical tests in the Cobres River basin. Nat Hazards 77(2):1205-1221. https://doi.org/10. 1007/s11069-015-1644-7

Silva RM, Santos CAG, Santos JYG (2018) Evaluation and modeling of runoff and sediment yield for different land covers under simulated rain in a semiarid region of Brazil. Int J Sediment Res 2:3. https://doi.org/10.1016/j.ijsrc.2017.04.005

Soares ASD, Da Paz AR, Piccilli DGA (2016) Avaliação das estimativas de chuva do satélite TRMM no Estado da Paraíba. Braz J Water Resour 21(2):288-299. https://doi.org/10.21168/ rbrh.v21n2.p288-299

Tabari H, Marofi S, Aeini A, Talaee PH, Mohammadi K (2011) Trend analysis of reference evapotranspiration in the western half of Iran. Agric For Meteorol 151(2):128-136. https://doi.org/10. 1016/j.agrformet.2010.09.009

Thomas T, Nayak PC, Ghosh NC (2015) Spatiotemporal analysis of drought characteristics in the Bundelkhand Region of Central India using the Standardized Precipitation Index. J Hydrol Eng 20(11):1-12. https://doi.org/10.1061/(ASCE)HE.1943-5584. 0001189

Vicente-Serrano SM, Beguería S, López-Moreno JI (2010) A multiscalar drought index sensitive to global warming: the standardized precipitation evapotranspiration index. J Clim 23:1696-1718

Wang X, Shen H, Zhang W, Cao J, Qi Y, Chen G, Li X (2014) Spatial and temporal characteristics of droughts in the Northeast China Transect. Nat Hazards 76:601-614. https://doi.org/10.1007/ s11069-014-1507-7

Wilhite DA, Hayes MJ, Svoboda MD (2000) Drought monitoring and assessment: status and trends in the United States. In: Vogt JV, Somma F (eds) Drought and drought mitigation in Europe. Kluwer Academic Publishers, Dordrecht, pp 149-160

WMO-World Meteorological Organization (2012) Standardized precipitation index user guide (M. Svoboda, M. Hayes and D. Wood). (WMO-No. 1090), Geneva. www.wamis.org/agm/pubs/ SPI/WMO_1090_EN.pdf

Xavier APC, Silva RM, Silva AM, Santos CAG (2016) Mapping soil erosion vulnerability using remote sensing and GIS: a case study of Mamuaba watershed, Paraíba State. Revista Brasileira de Cartografia (RBC) 68:1677-1688

Zeng H, Li L, Li J (2012) The evaluation of TRMM Multisatellite Precipitation Analysis (TMPA) in drought monitoring in the Lancang River Basin. J Geogr Sci 22(2):273-282. https://doi. org/10.1007/s11442-012-0926-1

Zhang Y, Li W, Chen Q, Pu X, Xiang L (2017) Multi-models for SPI drought forecasting in the north of Haihe River Basin, China. Stoch Environ Res Risk Assess 31:2471-2481. https://doi.org/ 10.1007/s00477-017-1437-5 